\title{
Multi-echelon agri-food supply chain network design integrating operational and strategic objectives: a case of public distribution system in India
}

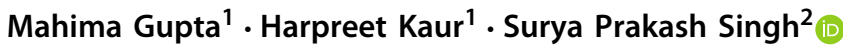

Accepted: 10 August 2021

(c) The Author(s), under exclusive licence to Springer Science+Business Media, LLC, part of Springer Nature 2021

\begin{abstract}
The global concern to ensure the availability of food for the growing world's population draws urgent attention towards the inefficiencies in agri-food supply chains. Agri-food supply chains are inherently complex to manage than other supply chains mainly because of their multi-echelon structure, deteriorating product quality with time and changes in storage conditions which leads to significant amount of food loss and wastage. Additionally, any natural or man-made disaster further disrupts the chain and leads to high food loss, high supply chain costs, reduced food availability and poor food quality. Hence, there is a need to design resilient and efficient agri-food supply chain network for optimal multi-echelon storage and distribution to reduce food loss and quality degradation. For this purpose, a Fuzzy Multi Objective Linear Program (FMOLP) is proposed in this paper for integrated food procurement, storage and distribution under cost, resilience and quality considerations. The proposed model integrates the short-term operational objective of cost optimization with the long-term sustainable objectives of food loss minimization and resilience maximization. The proposed FMOLP is illustrated using a realistic case of Public Distribution System using the data benchmarked with the numbers reported by the Food corporation of India. The detailed computational analysis carried out in the paper in investigates three categories of problem sizes to compare and contrast the decisions using different strategies and to provide organizational, operational and policy insights on the trade-off between cost, food loss and resilience.
\end{abstract}

Surya Prakash Singh
surya.singh@gmail.com

Mahima Gupta

mahima.gupta@iimamritsar.ac.in

Harpreet Kaur

harpreetk@iimamritsar.ac.in

1 Indian Institute of Management Amritsar, Amritsar, India

2 Department of Management Studies, Indian Institute of Technology Delhi, New Delhi, India 
Keywords Agri-food supply chain · Resilience · FMOLP · Multi-echelon · Food loss · TOPSIS

\section{Introduction}

It is one of the fundamental responsibilities of every government to ensure food availability for its people. Along with ensuring that enough food is being produced to feed the growing population (Smil, 2001), it is also equally important to ensure that the food distribution is transparent and efficient so that food loss/wastage can be minimized (Parfitt et al. 2010). Currently, agri-food supply chains are facing a lot of challenges related to food wastage, food quality and efficient use of resources (Yakovleva et al. 2012). Agricultural produce is highly perishable in nature. The quality of such products continuously deteriorates with time and depends on the conditions maintained while storage and transportation activities. This is the key reason for huge amount of food loss and wastage witnessed in agri-food supply chains (Musavi \& Bozorgi-Amiri, 2017). The multi-echelon structure of supply chains, operation inefficiencies within these echelon and lack of information sharing in agri-food supply chains further adds complexity (Gokarn \& Kuthambalayan, 2017). The inadequate temperature controlled and safe storage infrastructure at various stages of agri-food supply chains caused deterioration of food quality which results in high amount of food losses (Rajendran, 2003; Rong et al. 2011). Moreover, lack of coordination among various supply chain partners increases the risk of food contamination at various stages of supply chain which further raises the concern about the food quality and health of end consumers (Song \& Zhuang, 2017). Therefore, there is a need to develop effective and efficient storage and transportation networks for highly complex multi echelon food supply chains which minimizes the food loss and wastage and ensure the demand of each member of the supply chain is met without any delay (Manders et al. 2016; Zhu et al. 2018).

Agri-food Supply chains today are vulnerable to disruptions caused by many natural and man-made causes such as weather volatility, energy price fluctuations and logistics restrictions (Dani \& Deep, 2010; Diabat et al. 2012). It is especially important for food supply chains to be able to react to such disruptions ensuring that demand is met as it is the matter of sustenance for life (Barroso et al. 2011). The recent outbreak of COVID-19 pandemic which led to strict lockdown in various countries and disrupted manufacturing and logistics activities also raised concern on the resilience and responsiveness of food supply chains (Singh et al. 2021). In view of this, many researchers have attempted to combine different concepts of resilience from various disciplines and have proposed a resilience framework for food supply chains (Umar et al. 2017). However, it has been observed that most of the work done is on conceptualizing the resilience and identifying the potential risks in food supply chains. There is little work is done on modelling resilience in food supply chain networks (Manning \& Soon, 2016; Stone \& Rahimifard, 2018). It is important that the organization must consider strategic resilience as an important parameter while designing the food supply chain network.

It has been observed that most of the researchers have developed the models in order to optimize to optimize cost, carbon emissions and quality in the food distribution networks (Meneghetti \& Monti, 2015; Rossi et al. 2021; Sgarbossa \& Russo, 2017). Researchers have mainly focussed on short term operational decision while optimizing the network. However, in order to design resilient, responsive and well-coordinated agri-food supply chain networks, 
the strategic decisions such as location of storage and processing facilities plays a critical role. Therefore, it is important to integrate strategic and operational decisions.

To address the above-mentioned issues in the agri-food supply chain design, this paper proposes a two-stage approach. In the first stage, the strategic decision making for locating the suitable and resilient storage facilities by considering multiple criteria such as risk proneness, accessibility and operational ease is proposed using TOPSIS (The Technique for Order of Preference by Similarity to Ideal Solution). The resilience score is obtained for each potential site is taken as an input to the second stage for selecting the resilient locations to construct new storage facilities. In the second stage, strategic decision regarding selection of the location of new storage facilities for augmenting existing capacity in the supply chain is made along with the tactical and operational decisions of procuring and transporting the agricultural produce from markets to end customers in a multi-echelon complex network. For this purpose, the paper proposes a Fuzzy Multi-objective Linear Program (FMOLP) for joint storage facility site selection, determination of appropriate storage conditions and transportation of agricultural produce between different sites to meet demand over a multi-period time horizon. The problem is formulated as a multi-objective linear program to evaluate the alternatives on the three objectives namely cost minimization, food loss minimization and resilience maximization. Since these objectives are conflicting and non-commensurable in nature, a holistic solution is obtained with the help of fuzzy multiple objective programming problem. The proposed methodology is illustrated using the realistic case study of Public Distribution System (PDS) using the data adapted from Food Corporation of India's (FCI) website. In order to further understand the trade-offs between the objectives and implications of the proposed methodology, numerical trials are conducted on different problem instances with varying size. This approach leads to more sustainable decisions on PDS by simultaneously balancing short term operational objectives of minimizing the cost with long term strategic objectives of controlling food loss and enhancing resilience of the supply chain.

The rest of paper is structured as follows. Section 2 reviews the literature on grain movement \& storage problem. The proposed mathematical model and solution approach are discussed in Sect. 3. Section 4 illustrates the proposed framework with the help of an example. In Sect. 5, experiments are conducted to understand the trade-offs between different objectives under single focussed and fuzzy multiple objectives approach for different categories of the problem. The theoretical contributions and implications for policymakers are discussed in Sect. 6. Section 7 presents conclusions, limitations and future scope of work.

\section{Literature review}

Agri food supply chains plays a critical role in providing the basic necessities to the people (Smil, 2001). It is important that the food supply chain networks are transparent and efficient so that food loss/wastage can be minimized (Parfitt et al. 2010). Moreover, the food quality must be maintained during storage and transportation activities by ensuring proper infrastructure (Rajendran, 2003). In view of this, the literature is reviewed for food supply chain models in Sect. 2.1. Section 2.2 identifies the research gaps and research objectives for this paper. 


\subsection{Review of agri-food supply chain models}

This Section reviews the literature on agri-food supply chain models from two broad perspectives. Section 2.1.1 reviews the strategic planning and conceptual models which broadly focuses on studying the interplay of various supply chain actors and development of theory. Section 2.1.2 reviews the operational planning and analytical models for agri-food supply chain networks focussing mainly on optimization of short-term objectives.

\subsection{1 strategic planning models in agri-food supply chains}

Taylor (2006) proposed the use of lean principles in the strategic design of integrated food supply chain in order to improve overall chain performance. As agri-food supply chains are very unstable and dynamic, Matthews et al. (2007) have proposed the integrating of strategic management in supply chain decisions by analysing the markets and interrelationships among the companies. The collaboration among supply chain partners is of significant importance to agri-food industry. In this direction, Matopoulos et al. (2007) proposed a conceptual framework for collaboration development in agri-food supply chain and have linked the collaboration benefits to specific activities. Aramyan et al. (2007) have proposed a conceptual model to identify the dimensions for performance management in agri-food supply chains. However, it is important to understand the attitudes and circumstances of various supply chain partners while developing collaborative chains. Leat and Revoredo-Giha (2008) carried out an empirical study to highlight issues which hamper the collaboration in agri-food supply chains. Understanding and overcoming these issues can increase overall chain performance. Ahumada and Villalobos (2009) have reviewed the planning models used in agriculture production and supply chain and have expressed the concerns over limited research on integrated supply chain models leading to a gap in production and distribution activities. The outsourcing of certain supply chain functions can help in improving cost and reducing the waste. In context of agri-food supply chains, Hsiao et al. (2010) have proposed a decision-making framework to identify the determinants of outsourcing food logistics activities.

As the global population is increasing, the demand for food products is also increasing. Food supply chains are facing a major challenge to reduce the food loss and wastage at various stages. Highlighting the importance of agri-food supply chain management in order to ensure food availability, Kusumastuti et al. (2016) have reviewed the literature for complexities in ASC such as yield uncertainties, inventory, resource limitations, time windows and coordination between several supply chain entities. Manders et al. (2016) have identified various dimensions of supply chain flexibility which is essential in maintaining cost and quality in agri-food supply chains. Chaboud (2017) emphasized on the need to assess and report the food loss and wastage in agri-food supply chains. It is important to locate the major areas responsible for food loss so that efficient supply chains can be designed in an attempt to reduce the food wastage and maintain the food quality. Gokarn and Kuthambalayan (2017) have identified key inhibitors to manage food wastage in Indian agri-food supply chains and have established the inter-relationships among these inhibitors. Govindan (2018) emphasized on the importance of coordinating the multi echelon food supply chain in order to minimize the food loss and ensure sustainability. In agri-food supply chains, the functions such as storage and transportation are inherently more energy intensive due to the need for refrigeration in order to maintain quality. Therefore, the design of supply networks must consider the emissions caused. Awad et al. (2020) have reviewed the research in cold food supply chain and emphasized on the need for integration of quality and environmental consideration in vehicle and route planning. Esteso et al. (2018) reviews the literature in 
Agri-food supply chain with a special focus on the inherent characteristics of agricultural produce and the sources of uncertainty. It is important to consider these two important factors while designing food supply chain networks in order to improve the chain performance and maintain food quality.

Different kinds of disruptions require different strategies to recover. Dani and Deep (2010) have identified the factors required for effective response to the food supply chain risks and have applied the conceptual model to different cases of supply chain risks. Manning and Soon (2016) introduced the concept of building strategic resilience in food supply chains and have proposed a resilience indicator to assess and improve supply chain risk. Umar et al. (2017) emphasized on the need for more research in food supply chain resilience. The quantification and modelling of risk and resilience in food supply chains is identified as major research gap. The conceptual framework for food supply chain resilience in proposed. Stone and Rahimifard (2018) proposed a resilience framework and have identified the elements of resilience in order to handle disruptions in agri-food supply chains. Song and Zhuang (2017) proposed a game theory-based framework to control the risk of food contamination at various stages of the supply chain considering the interactions between governments, farmers and other supply chain actors. Shareef et al. (2020) have identified the lack of coordination between multiple echelons of a supply chain is one of the key reasons for the failure of supply chains to respond in emergency situations. Therefore, in order to have a resilient food supply chain network, proper coordination among multiple stages of the chain starting from farm to the end customer is required. Esteso et al. (2021) argued that the product perishability in agri-food supply chain must be considered as a strategic decision rather than considering it to be an operational or tactical decision. Therefore, the network design of agri-food supply chains must consider the perishable nature of produce. Recently, Khan et al. (2021) have studied the impact of food supply chain disruption due to Covid-19 on the undernourishment of population and crime in Asian countries. This study clearly outlines the need to design resilient and more transparent food supply chains in order to have a better society.

\subsubsection{Operational planning models in agri-food supply chains}

In agri-food supply chains, end to end supply chain integration is required to monitor the food quality and reduce the food loss/wastage. There are some papers attempting to model various operational activities and decisions in agri-food supply chains. In this direction, Nardi et al. (2007) have proposed a mathematical program to optimize the storage and transportation of soybean in Argentina considering geographical data. Bilgen and Ozkarahan (2007) have proposed a model for grain blending and transportation using maritime transportation in order to optimize the number of vessels to be hired for the bulk movement. Van Der Vorst et al. (2009) have proposed a simulation-based approach to model flexibility into food supply chain subject to uncertainties and food quality changes. Hu and $\mathrm{Wu}$ (2010) have modelled and compared the different agri-food supply chain models in China and have proposed the integration of all supply chain functions to ensure food safety and competitiveness. Deterioration of food quality leading to high amount of food loss is a major concern in agri-food supply chains. To address this, Rong et al. (2011) have integrated the food quality degradation function in designing the food distribution to jointly optimize food quality as well as cost of distribution. Paksov et al. (2012) have proposed a fuzzy multi objective model to optimize the total transportation cost across multiple echelons of a supply chain. Agsari et al. (2013) have proposed the supply chain network model for movement of wheat from farms to end customers located either in same province or separate province. Since agri-food supply chains are highly energy intensive, there is also a growing concern over sustainability 
of the network design. In this direction, Soysal et al. (2014) have proposed a multi-objective mixed integer model to optimally plan food logistics in order to optimize carbon emissions and cost considering a variety of factors such as road infrastructure, vehicle $\&$ fuel types, distance travelled etc. Meneghetti and Monti (2015) have modelled an automated storage and retrieval system for refrigerated items such that quality degradation as well as energy consumption is minimized. The model can aid in the reconfiguration of food supply chains. Soto-Silva et al. (2016) have reviewed the application of operations research models in fresh fruit supply chain. In an attempt to minimize the high amount of wastage in food supply chains, Banasik et al. (2017) proposed a multi objective production planning model to establish trade-off between economic objectives and environmental objectives for a processed food supply chain. Sgarbossa and Russo (2017) have proposed a sustainable closed loop model to recover waste from a meat processing industry.

Supply chain models need to be designed in such a way that there is a coordinated flow of material not just with in an enterprise but also across all supply chain partners. Therefore, Gholamian and Taghanzadeh (2017) have proposed an integrated network model for wheat supply chain in Iran by addressing supplier selection, silo storage decisions and distribution of wheat and wheat products to end customers. Mohammed and Wang (2017) developed a fuzzy multi-objective program to simultaneously optimize carbon emissions, cost, distribution time and delivery rate. Soysal et al. (2018) have explored the horizontal collaboration between the suppliers for inventory routing to jointly optimize the energy usage, carbon emissions and total cost which also includes the wastage cost. It is observed that horizontal collaboration leads to less cost and carbon emissions. Stellingweft et al. (2018) studied the effects of logistics cooperation models i.e. vendor managed inventory and joint route planning on the performance of temperature controlled fresh food supply chain. It was observed that the multi echelon cooperation among supply chain partners lead to substantial cost and carbon emission savings as compared to individual route planning. Recently, Jouzdani and Govindan (2021) have proposed a multi-objective model to design sustainable supply chain networks for perishable items by studying interactions between three aspects of sustainability.

With increased risk of supply chain disruptions due to any natural or manmade disaster, the evaluation and assessment of risk in agri-food supply chains is getting a lot of attention from researchers. Diabat et al. (2012) have developed a structural model to analyse various types of risks in food industry and have discussed the mitigation strategies for the same. Bi and Zhang (2016) have proposed the emergency food storage model to facilitate relief operations. Similarly, Fan and Zhang (2016) have developed models for locating emergency grain depots and for the allocation of grains against uncertain demand establishing a trade-off between the budget and the desired service level. Kaveh and Mesgari (2019) have proposed a GIS based location-allocation model for location of emergency centres enabling maximum coverage in any disaster event. Kaveh et al. (2020) have proposed a multi-criteria decision-making model for the site location of hospital emergency centres. Recently, Yakavenka et al. (2020) have proposed a multi objective model to optimally design a perishable food supply chain network by establishing trade-offs between three dimensions of sustainability. However, many models do not consider the need to incorporate resilience into the network design. Mohammed et al. $(2019,2021)$ have emphasized on the designing the sustainable as well as resilient supply chain networks in order to maximize the chain performance. Bhottani et al. (2019) modelled resilient supply chain network considering raw material disruptions in order to ensure business continuity of operations. It is important that food supply chain networks are resilient so that the supply of food items is not disrupted under any unforeseen natural or manmade disaster. The performance of a supply chain is dependent on the ability of the chain to handle uncertainties occurring at the various stages. Mohebalizadehgashti 
et al. (2020) have proposed a multi-objective model to focus on environmental concerns and effective utilization of resources while optimizing food supply chain networks under uncertainty. In order to address uncertainty, decision trees are used.

\subsection{Research gaps and research objectives}

This Section identifies the research gaps from the reviewed literature and presents the research objectives for this paper.

\subsubsection{Research gaps}

Following are the research gaps identified from the reviewed literature which the paper attempts to address by developing the proposed methodology.

- Many papers focus on optimizing the cost, quality and carbon emissions in the agrifood supply chain networks. Most of the frameworks or models proposed in literature are operational and tactical planning. There is a little research on the strategic design of agrifood supply chains for better coordination among multi-echelon supply chain structures.

- There is very limited research on the resilience in agri-food supply chain networks. A very few papers talk about the need of building strategic resilience, however, there is very limited work on modelling the resilience in agri-food supply chain networks.

- The researchers have worked independently on developing strategic frameworks and operational models. There is very little attempt made to jointly address long term strategic objectives such as resilience along with short term operational objectives such as cost and quality in a single framework.

Considering the research gaps stated above, it is evident that there is a need to design resilient and efficient agri-food supply chain networks which allows well-coordinated storage and movement across multiple echelons of the chain. The network design must jointly address the short-term objectives of cost and waste minimization along with the long-term objective of developing the resilience in the supply chain.

\subsubsection{Research objectives}

Following are the research objectives framed to address the gap areas.

- To obtain the resilience score of potential sites for storage facilities at various levels of a multi-echelon agri-food supply chain considering both quantitative and qualitative criteria

- To propose a Fuzzy Multi objective Mixed Integer Program (FMOLP) for integrated and well-coordinated decision making in procurement, storage and transportation in a multiechelon agri-food supply chain by simultaneously minimizing operational objectives of cost and wastage and strategic objective of maximizing resilience in the chain.

- To propose a solution methodology to obtain an optimal trade-off between three conflicting objectives (operational \& strategic) and carry out detailed computational analysis to compare the decisions using different strategies 


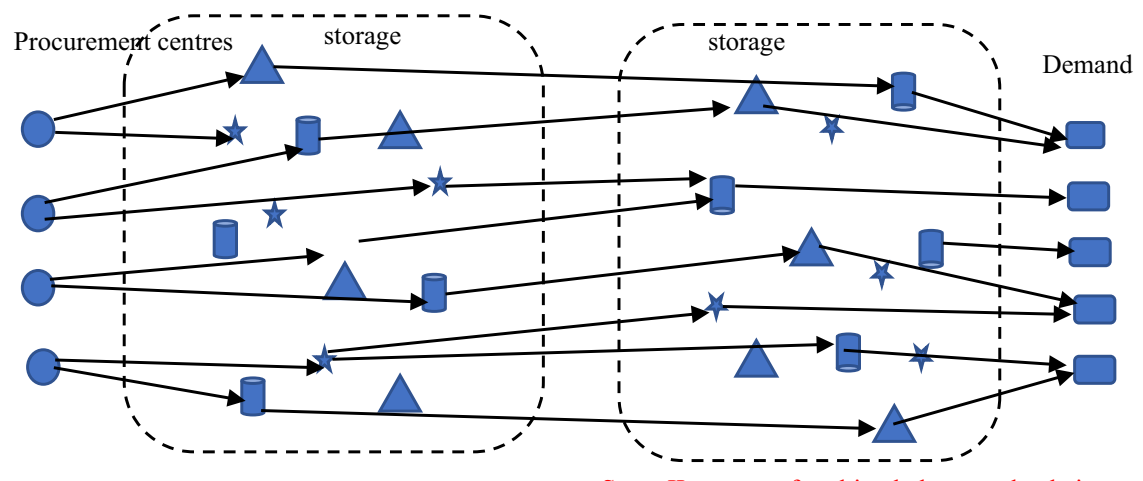

Stage -I storage of multi-echelon supply chain

Stage II storage of multi-echelon supply chain

Godowns

Existing Silos

$\triangle$

New Silos

Fig. 1 Multi-echelon agri-food supply chain structure

\section{Problem statement and proposed methodology}

\subsection{Problem statement}

In this paper, a multi-echelon agri-food supply chain problem is considered. There is a need to identify the storage capacities at various levels of multi-echelon supply chain and locate additional storage facilities (if necessary) at suitable locations which maximizes network resilience. In additional, there is also a need to design well-coordinated procurement, storage and distribution decisions which minimizes the overall cost and food loss in the chain along with maximizing the resilience. The multi-echelon supply chain structure is shown in Fig. 1. The proposed problem statement attempts to address short-term operational objectives i.e. cost and waste minimization and the long-term strategic objective i.e. maximizing the network resilience using a single framework.

\subsection{Proposed methodology}

In order to address the problem described in Sect. 3.1, the paper proposes a Fuzzy Multiple Objective Linear Model (FMOLP) for integrated procurement, storage and distribution across a multi-echelon agri-food supply chain. The proposed framework addresses the longterm strategic objective of locating the storage facilities in such a way that it maximizes the overall network resilience as shown in Fig. 2. The resilience of the potential site is assessed from multiple perspectives using a multi criteria decision making (MCDM) method (discussed in Sect. 3.2.1). Further, in the Sect. 3.2.2, the relationship between food wastage and sub-optimal storage temperature is established using a quality degradation function. The integrated decision on procurement, storage and transportation is formulated as a fuzzy multiobjective linear programming problem in Sect. 3.2.3 considering operational objectives of cost and waste minimization and strategic objective of network resilience maximization. In order to solve the proposed FMOLP considering multiple conflicting objectives, a fuzzy goal programming-based solution methodology is discussed in Sect. 3.2.4 


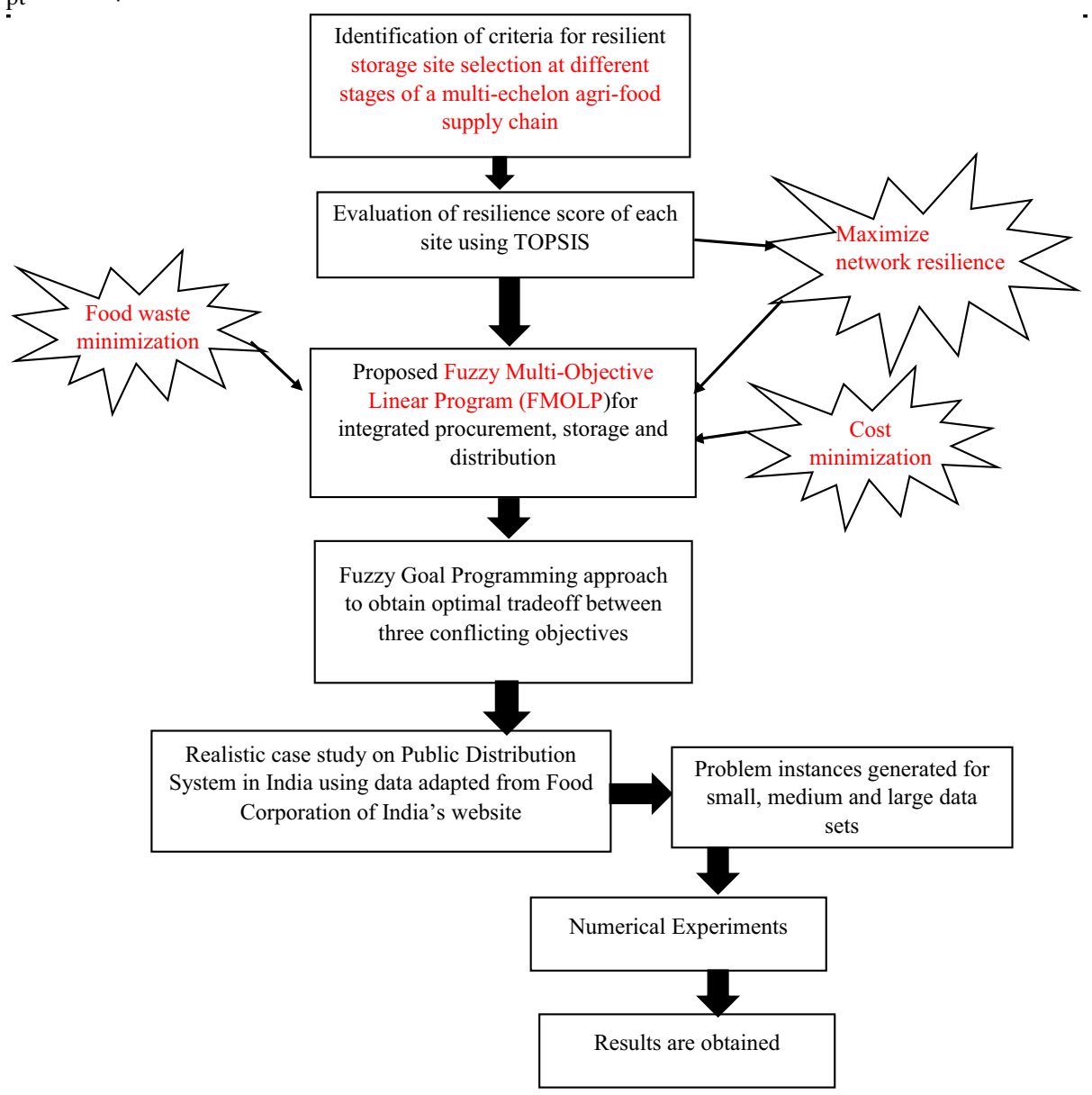

Fig. 2 Proposed Research Methodology

\subsubsection{Calculation of resilience index}

Any supply chain network should have capability to reduce the vulnerability against disruptions, absorb disaster impact and quickly recover from disruption to ensure desired level of food availability following a disaster (Sheffi \& Rice, 2015). In agri-food supply chains, the main reason for high food loss \& wastage is the lack of proper storage infrastructure (Tanksale \& Jha, 2015). It is necessary that multi-echelon agri-food supply chains should evaluate the existing storage capacities available in the network and new facilities must be located in such a manner that it augments the overall resilience of the entire network. To comprehensively evaluate the location and select the optimal one, diverse factors are needed to be taken into consideration. The considered criteria take care of the operational ease of the potential sites by assessing the utilities and railway siding available at the site. The geographical features of the proposed sites are also considered in order to access the disaster resilience of the proposed site. A summary of the relevant variables from the literature is given in Table 1 below.

The sites are evaluated in this Section based on the list of criteria and are prioritized using the TOPSIS. TOPSIS (Technique for preference by similarity to ideal solution) proposed by 


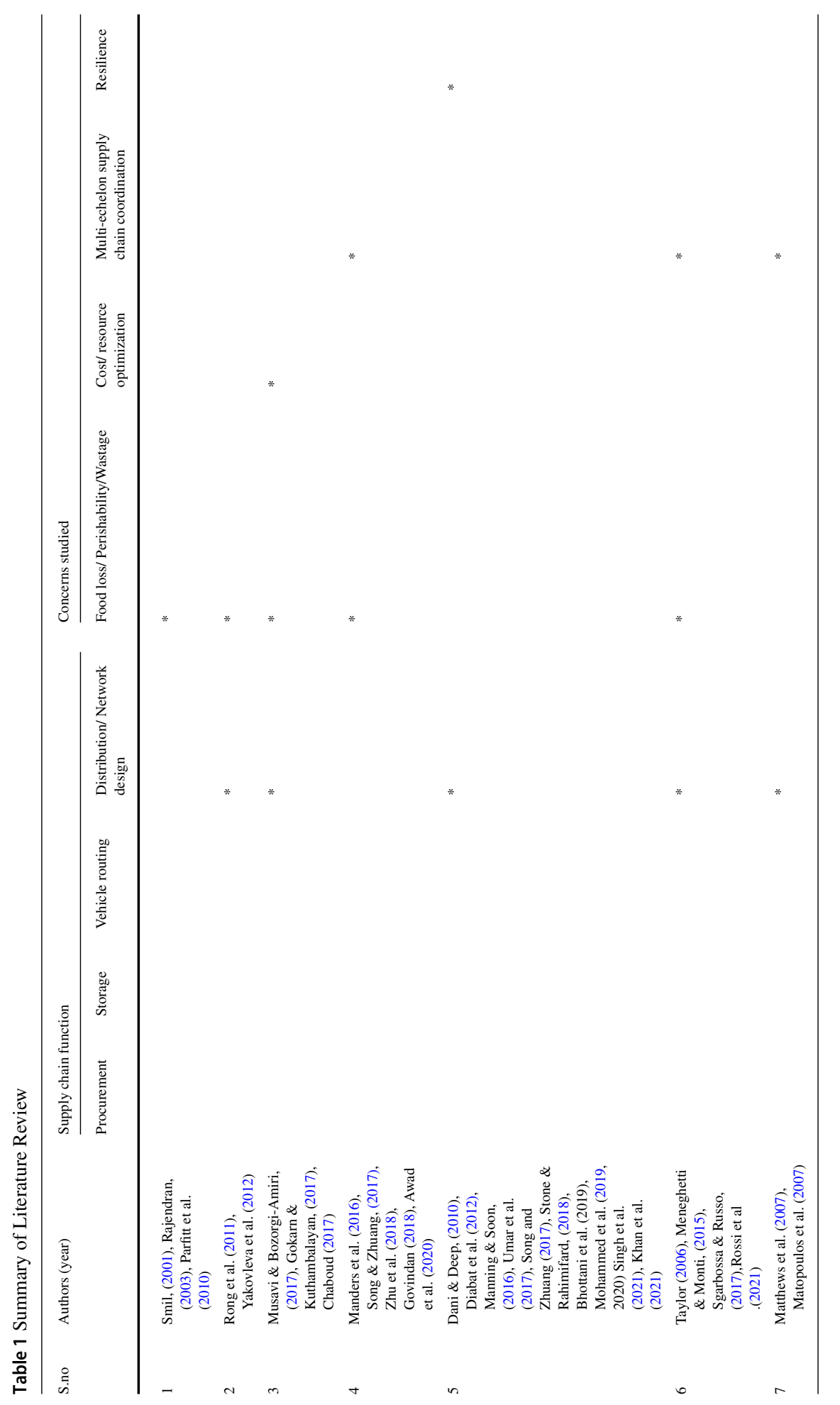

\section{를 Springer}




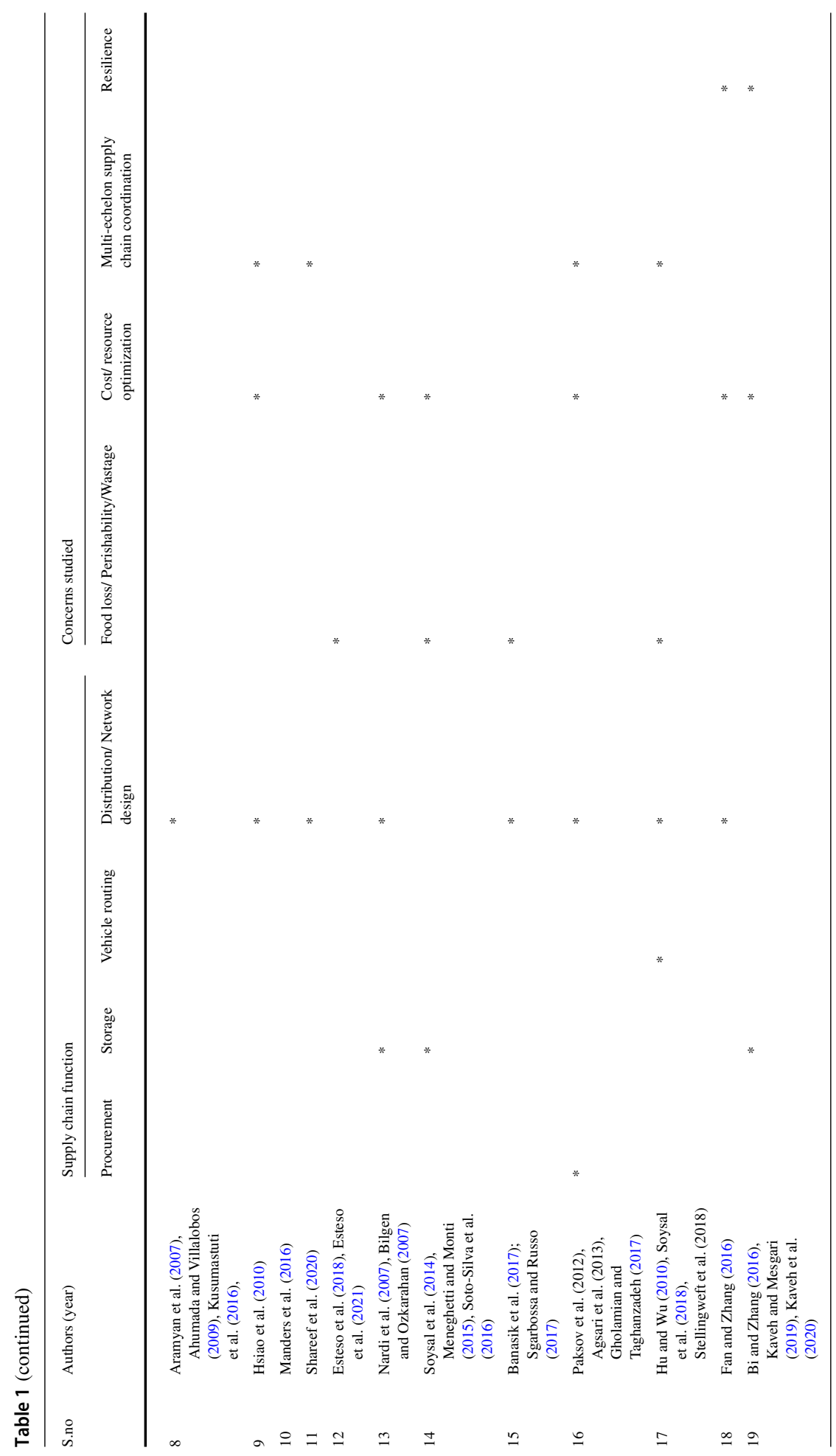




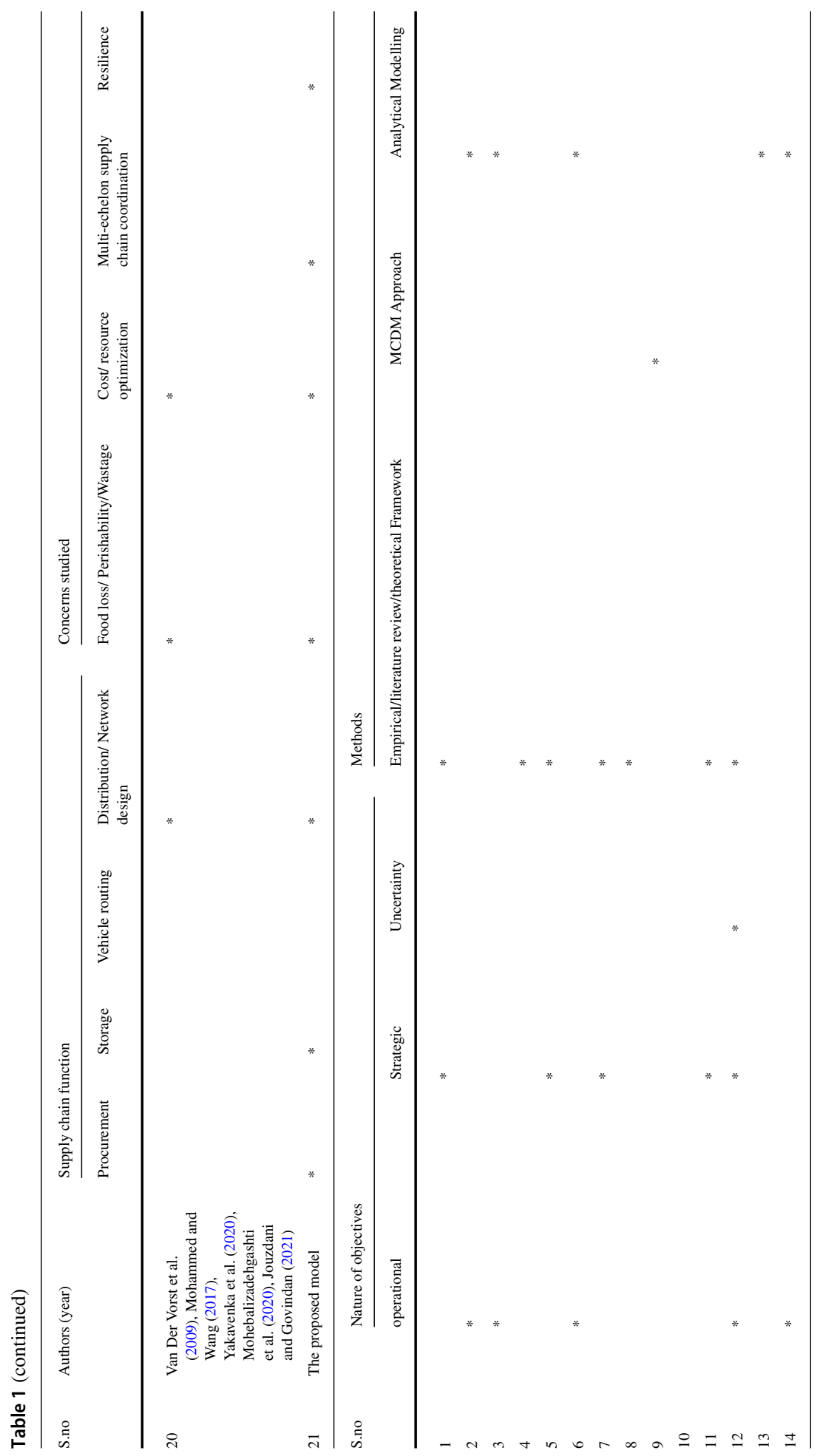

\section{를 Springer}




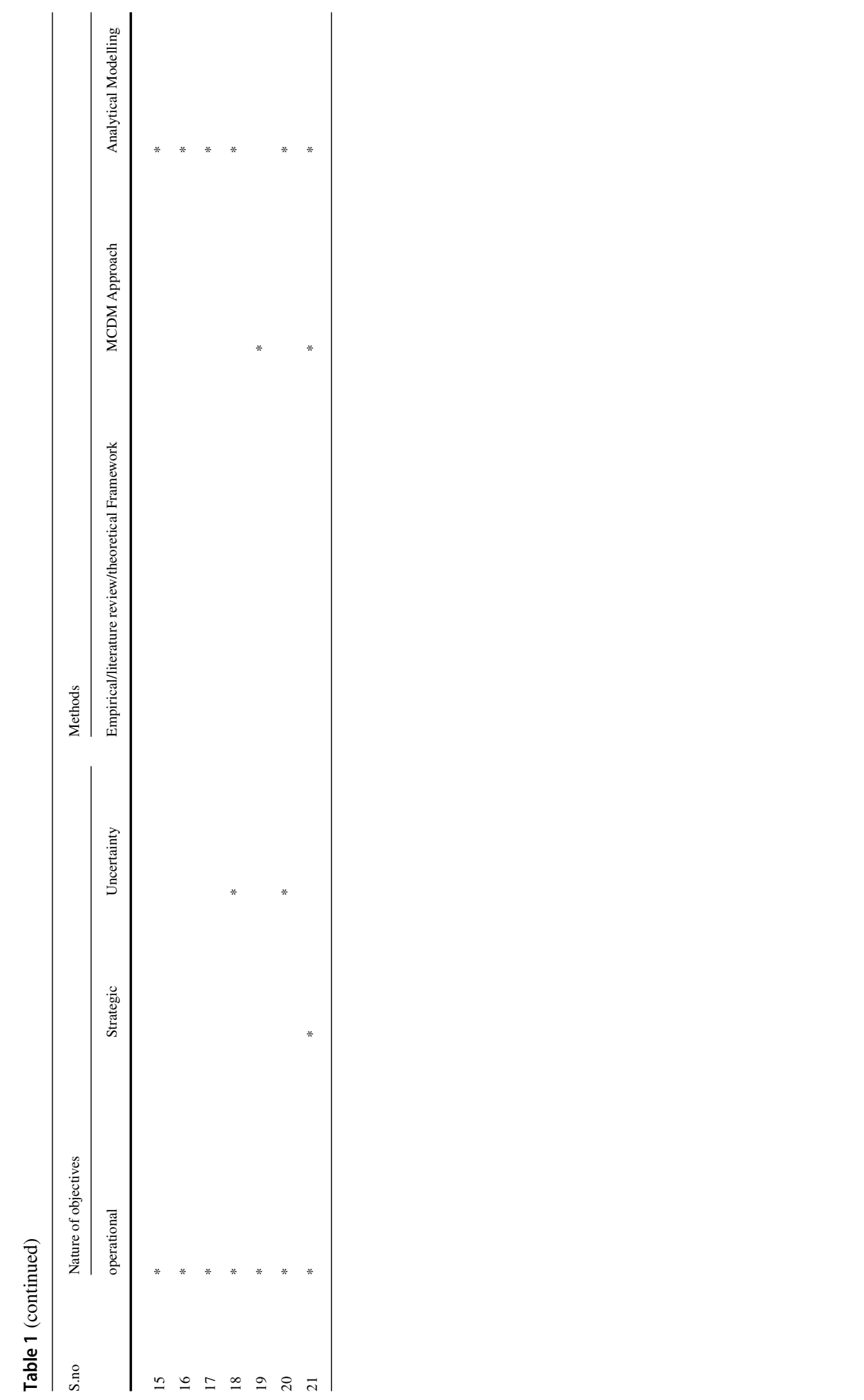


Table 2 Criteria for Site selection

\begin{tabular}{|c|c|c|}
\hline Criteria & Description & References \\
\hline Availability of Rail siding $\left(\mathrm{C}_{1}\right)$ & $\begin{array}{l}\text { Whether the site has a railway siding } \\
\text { adjacent to it? Or construction of } \\
\text { separate railway siding is required }\end{array}$ & Tanksale and Jha (2015) \\
\hline Space $\left(\mathrm{C}_{2}\right)$ & What is the space availability at the site? & Özcan et al. (2011) \\
\hline Proximity to mandis $\left(\mathrm{C}_{3}\right)$ & $\begin{array}{l}\text { Total distance of the site from various } \\
\text { mandis must be minimum and accessible }\end{array}$ & Demirel et al. (2010) \\
\hline $\begin{array}{l}\text { Frequency of cyclones \& } \\
\quad \text { flooding, and overall Terrain } \\
\left(\mathrm{C}_{4}\right)\end{array}$ & $\begin{array}{l}\text { The site must be chosen carefully to avoid } \\
\text { disruptions from disaster occurrences, } \\
\text { higher terrain }\end{array}$ & $\begin{array}{l}\text { Roh et al. (2013), Zhang } \\
\text { and Chen (2016) } \\
\text { Storage Mannual (FCI) }\end{array}$ \\
\hline Seismicity $\left(\mathrm{C}_{5}\right)$ & $\begin{array}{l}\text { The silo must be constructed in regions of } \\
\text { low seismicity }\end{array}$ & Storage Manual (FCI) \\
\hline $\begin{array}{l}\text { Surrounding population density } \\
\left(\mathrm{C}_{6}\right)\end{array}$ & $\begin{array}{l}\text { The population density around the silo } \\
\text { location must not be very high }\end{array}$ & $\begin{array}{l}\text { Raut et al. (2017), Zhang } \\
\text { and Chen (2016) }\end{array}$ \\
\hline Utility supply at the site $\left(\mathrm{C}_{7}\right)$ & $\begin{array}{l}\text { The availability of utilities such as } \\
\text { electricity, water and gas supply etc. at } \\
\text { the site }\end{array}$ & Demirel et al. (2010) \\
\hline Local government policies $\left(\mathrm{C}_{8}\right)$ & $\begin{array}{l}\text { The level of support extended by the local } \\
\text { government bodies }\end{array}$ & $\begin{array}{l}\text { Roh et al. (2013), Raut } \\
\text { et al. (2017) }\end{array}$ \\
\hline
\end{tabular}

Hwang and Yoon (1981) is a well-established and widely used multi criteria decision making method to rank a set of alternatives i.e. sites in this case. Following are the steps involved in TOPSIS.

Step-I: Data is obtained for all potential sites $j$ against the considered criteria $i$ as shown in Eq. (1)

$$
a_{i j}=\left|\begin{array}{lll}
d_{11} & d_{21} & d_{i 1} \\
d_{12} & d_{22} & d_{i 2} \\
d_{1 j} & d_{2 j} & d_{i j}
\end{array}\right|
$$

Step-II: A standardized matrix $\mathrm{S}_{\mathrm{ij}}$ is obtained by using Eq. (2)

$$
S_{i j}=\frac{d_{i j}}{\left(\sum_{j} d_{i j}^{2}\right)^{1 / 2}} \quad \forall i, j
$$

Step III: Weights are developed for each criterion as $\left(\mathrm{w}_{\mathrm{j}}\right)$ and weighted normalized matrix is constructed using Eq. (3)

$$
V_{i j}=w_{j} S_{i j} \quad \forall i, j
$$

However, if all the criteria are equally weighted than it will be exactly same matrix as step II.

Step-IV: The ideal solution is identified using Eq. (4)

$$
\text { Idealsolution } V^{*}=\left\{\max \left(V_{i j}\right) \quad \forall i\right\}
$$

Step V: Similarly, the negative-ideal solution is identified using (5).

$$
\text { NegativeIdealsolution } V^{\prime}=\left\{\min \left(V_{i j}\right) \quad \forall i\right\}
$$


Step VI: The Separation Measure $\left(\mathrm{S}_{\mathrm{i}}{ }^{*}\right)$ is calculated for each potential site from the ideal solutions as shown in Eq. (6)

$$
S_{i}^{*}=\sum_{j}\left(\left(V^{*}-V_{i j}\right)^{2}\right)^{1 / 2} \quad \forall i
$$

Step VII: Similarly, the separation measure $\left(\mathrm{S}_{\mathrm{i}}{ }^{\prime}\right)$ is calculated for each potential site from negative ideal solution as shown in Eq. (7)

$$
S_{i}^{\prime}=\sum_{j}\left(\left(V^{\prime}-V_{i j}\right)^{2}\right)^{1 / 2} \quad \forall i
$$

Step VIII: The closeness index is computed using Eq. (8) and the potential sites are ranked in descending order of the index value.

$$
C_{i}^{*}=\frac{S_{i}^{\prime}}{\left(S_{i}^{\prime}+S_{i}^{*}\right)} \quad \forall i
$$

The site having highest closeness index is most resilient and is more preferred for silo construction. The resilience of the sites become input to the mixed integer linear programming model discussed in Sect. 3.2.3.

\subsubsection{Integration of grain wastage and temperature control}

It is usually observed that the storage facilities in multi-echelon agri-food supply chain networks are old fashioned and don't use modern or temperature control storage technology. In order to sustain the quality of agricultural produce and minimize the degradation in product quality during the storage, the supply chain partners must enhance effectiveness of its storage capacity by introducing temperature-controlled storage at various stages of the chain. The proposed modernized storage facility provides temperature-controlled environment that aids in controlling food quality degradation during storage. The proposed model assumes that the silo type of storage system (both existing and new) provides a temperature-controlled environment for agricultural produce. There are different temperatures which can be maintained which helps in significantly reducing the food loss during storage. This study conceptualizes the food loss during storage as a function of temperature at the storage facility. At each temperature point, there is a corresponding operational cost and a degradation rate. Let $T P_{1}$ to $T P_{5}$ be five temperature points such that $T P_{1}<T P_{2}<\ldots<T P_{5}$ at which agricultural produce could be stored with the observed degradation rates are $d_{1}$ to $d_{5}$ such that $\mathrm{d}_{1}>\mathrm{d}_{2} \ldots$. $>\mathrm{d}_{5}$. The degradation rate observed at silo storage is less than the degradation happening in traditional storage facilities i.e. godowns. For instance, if the agricultural inventory ' $I$ ' is stored at a temperature $T P_{2}$ at any silo in a particular time period, the food loss would amount to be $I^{*} d_{2}$ during the time period. Therefore, the remaining agricultural inventory in the next time period would be equal to $I^{*}\left(1-d_{2}\right)$ units. The controlling of temperature at the lower value incurs additional operational cost, therefore, the cost of holding increases with the decrease in temperature i.e. $c_{1}>c_{2}>c_{3}>c_{4}>c_{5}$.

\subsubsection{Fuzzy multi objective linear program (FMOLP)}

This Section proposes a Fuzzy Multi Objective Linear Program (FMOLP) to jointly optimize the procurement, storage location \& transportation in a multi-echelon agri-food supply chain. 
The agricultural produce is procured at various procurement centres and are transported to the storage facilities at stage -I of a multi-echelon supply chain. The model assumes that procurement is one-time activity and is conducted within a period during harvest. There are two type of storage facilities considered to be already functional i.e. traditional godowns and existing temperature-controlled silos. At godowns, the temperature is not controlled and hence, the degradation rate of the agricultural produce is higher here than in the silo storage. At silos, agricultural produce is stored at different temperature points and are transported to storage facilities at stage -II of a multi-echelon supply chain. The agricultural produce is then transported to demand centres to meet their demand over the planning horizon. There can be a scenario that the storage facilities at stage I \& stage II of multi-echelon supply chain are inadequate, therefore, there is a need to identify the potential sites for the construction of new temperature-controlled storage facilities such that resilience of the site and overall operating expenses can be simultaneously optimized. Therefore, the stated problem is formulated as multi objective joint location-transportation model that aids in deciding the quantities of agricultural produce transported and stored within several stages of a multi-echelon supply chain i.e. from procurement centres to storage facilities and to demand centres, and also identify the location of new storage silos required at the different stages.

The list of assumptions, indices, variables and parameters used to model the problem are shown below:

List of assumptions

- The quantity of agricultural produce procured at each procurement centre is known with certainty.

- The procurement centres procure all the agricultural produce and send it for storage in godowns or silos at stage I of a multi-echelon supply chain.

- There are already functional godowns and silos being used for storage. However, in case of lack of storage capacity, new temperature-controlled silos need to be built and used.

- At each stage of a multi-echelon supply chain, there are several sites under consideration for new silo construction

- Each site under consideration for silo construction is having a "Resilience Index"

- The godowns are not temperature controlled. However, silo structures store food grains at a particular temperature in a time period

Indices

$\begin{array}{ll}m & \text { Index for procurement centres } \\ g & \text { Index for godowns at stage I of a multi-echelon supply chain } \\ \mathrm{g}, & \text { Index for godowns at stage II of a multi-echelon supply chain } \\ e & \text { Index for existing silos at stage I of a multi-echelon supply chain } \\ \mathrm{e} & \text { Index for existing silos in stage II of a multi-echelon supply chain } \\ s & \text { Index for Site for new silos at stage I of a multi-echelon supply chain } \\ \mathrm{s}, & \text { Index for site for new silo in stage II of a multi-echelon supply chain } \\ q & \text { size of silos to be constructed } \\ \mathrm{r} & \text { Index for retail or demand points } \\ \mathrm{t} & \text { Index for time period } \\ \mathrm{T} & \text { Index for temperature }\end{array}$




\section{Decision variables}

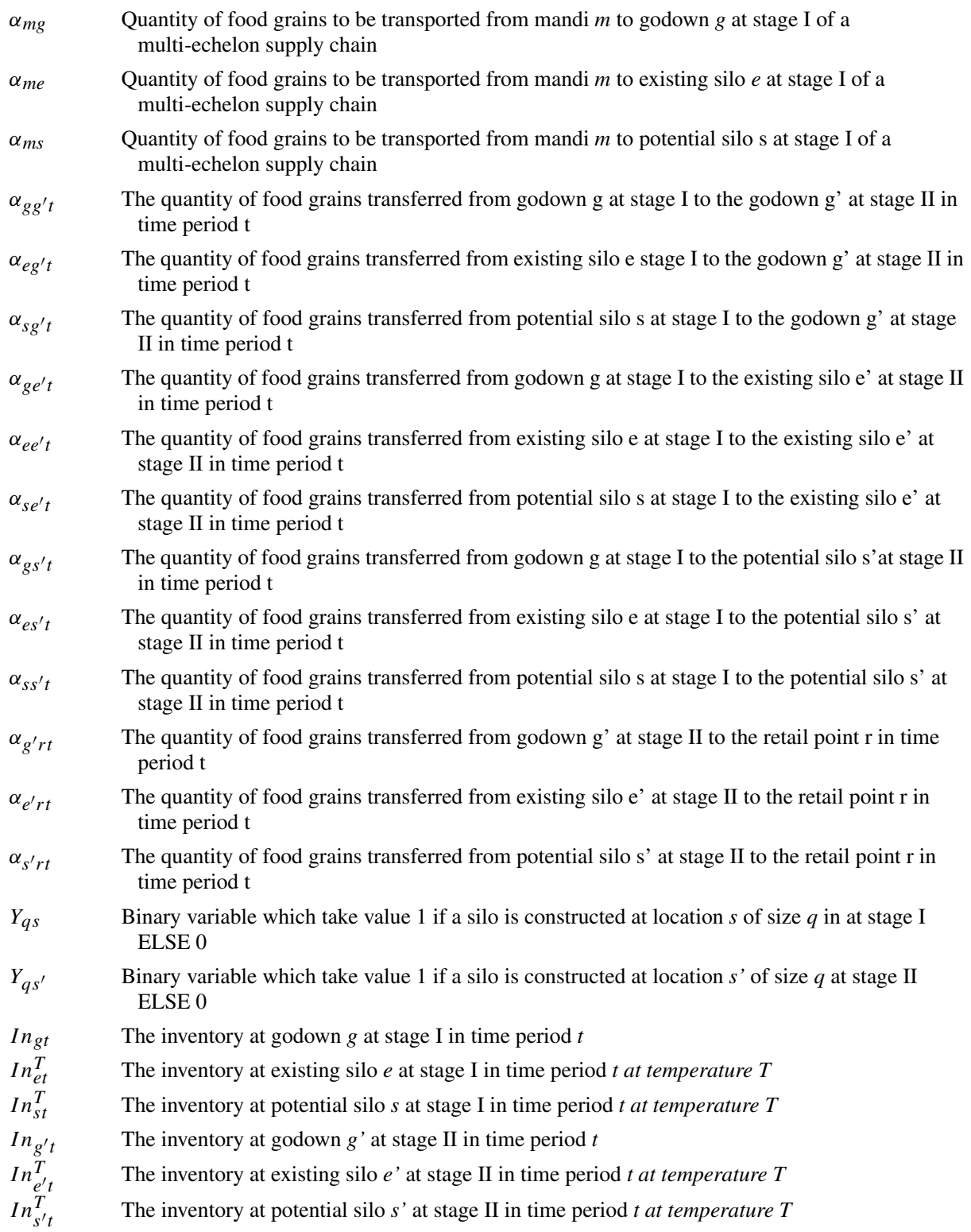




\section{Parameters}

Capg Capacity of godown g at stage I

$\mathrm{Cap}_{e}$ Capacity of existing silo e at stage I

$G P_{m}$ Grain procured at procurement centre $\mathrm{m}$ at stage I

$C C_{s q}$ Cost of constructing silo at site $s$ of size $q$ at stage I

$C C_{s^{\prime} q}$ Cost of constructing silo at site $s^{\prime}$ of size $q$ at stage II

$C R_{S}$ Cost of constructing railway siding at location $\mathrm{s}$ at stage I

$C T_{m g}$ Cost of unit transportation from procurement centre $m$ to godown $g$ at stage I

$C T_{m e}$ Cost of unit transportation from procurement centre $m$ to existing silo $e$ at stage I

$C T_{m s}$ Cost of unit transportation from procurement centre $m$ to potential silo $s$ at stage I

$D S_{m g}$ Distance in Kmts from procurement centre $m$ to godown $g$ at stage I

$D S_{m e}$ Distance in Kmts from procurement centre $m$ to existing silo $e$ at stage I

$D S_{m s}$ Distance in Kmts from procurement centre $m$ to potential silo site $s$ at stage I

$N p$ Maximum silos that can be constructed at stage I

$N c$ Maximum silos that can be constructed at stage II

$R P s$ Indicatortake value 1 if rail siding needs to be constructed at location $s$ at stage I

$R C s$ Indicator take value 1 if rail siding needs to be constructed at location $s$ at stage II

$T C R$ The per tonne transportation cost by Road for per unit distance travelled

TCT The per tonne transportation cost by Rail for per unit distance travelled

$P_{i j}$ The proportion of distance travelled by road between nodes $\mathrm{i}$ and $\mathrm{j}$ where

$i \in\{g+e+s\} \& j \in\left\{g^{\prime}+e^{\prime}+s^{\prime}\right\}$

$d_{i j}$ Distance in Kmts between nodes i and $\mathrm{j}$ where $i \in\left\{g+e+s+g^{\prime}+e^{\prime}+s^{\prime}\right\} \& j \in\left\{g^{\prime}+e^{\prime}+s^{\prime}+r\right\}$

$H C_{g t}$ Per unit holding cost at godown $g$ at stage $\mathrm{I}$ in time period $t$

$H C_{e t}^{T}$ Per unit holding cost at existing silo $e$ at stage I in time period $t$ stored at temperature $T$

$H C_{s t}^{T}$ Per unit holding cost at potential silo $s$ at stage $\mathrm{I}$ in time period $\mathrm{t}$ stored at temperature $T$

$H C_{g^{\prime} t}$ Per unit holding cost at godown $g^{\prime}$ at stage II in time period $t$

$H C_{e^{\prime} t}^{T}$ Per unit holding cost at existing silo $e^{\prime}$ at stage II in time period $t$ stored at temperature $T$

$H C_{s^{\prime} t}^{T}$ Per unit holding cost at potential silo $s^{\prime}$ at stage II in time period t stored at temperature $T$

$d$ : Degradation rate of godowns at stage I \& II

$d_{T}^{e}$ Degradation rate of existing silo at stage I at temperature $\mathrm{T}$

$d_{T}^{S}$ Degradation rate of potential silo at stage I at temperature $\mathrm{T}$

$d_{T}^{e}$ : Degradation rate of existing silo at stage II at temperature $\mathrm{T}$

$d_{T}^{S}$ : Degradation rate of potential silo at stage II at temperature T

$C_{s}^{*}$ : Resilience Index of potential silo $\mathrm{s}$ at stage I

$C_{s^{\prime}}^{*}$ : Resilience Index of potential silo s' at stage II

The constraints for the problem are discussed below:

Capacity constraints at stage I of the multi-echelon agri-food supply chain

$$
\begin{aligned}
& \sum_{m} \alpha_{m g p} \leq \operatorname{Cap}_{g p} \quad \forall g \\
& \sum_{m} \alpha_{m e p} \leq \operatorname{Cap}_{e p} \quad \forall e
\end{aligned}
$$




$$
\begin{gathered}
\sum_{m} \alpha_{m s} \leq \sum_{q}\left(\operatorname{Cap}_{q s} * U_{q s}\right) \quad \forall s \\
\sum_{g} \alpha_{m g}+\sum_{e} \alpha_{m e}+\sum_{s} \alpha_{m s}=G P_{m} \quad \forall m
\end{gathered}
$$

Constraints (9) and (10) enforce that the agricultural produce to be transported from various procurement centres to the godowns and existing silos at stage I storage must be less than or equal to their respective available capacity. Constraint (11) states that the total quantity transported from a procurement centre to a new silo storage, if required, should be less than its capacity. Constraint (12) ensures that total agricultural produce transported from various procurement centres to the stage I storage facilities should be equal to their procured quantities.

$$
\begin{gathered}
\sum_{q} U_{q s} \leq 1 \forall s \\
\sum_{s} \sum_{q} U_{q s} \leq N
\end{gathered}
$$

Constraint (13) restricts that only one size of silo can be constructed at the potential site at stage I of multi-echelon supply chain. Constraint (14) restricts the total number of silos constructed at stage-I to maximum number of silos sanctioned to be constructed at that particular stage of supply chain.

$$
\begin{gathered}
\sum_{g} \alpha_{g g^{\prime} t}+\sum_{e} \alpha_{e g^{\prime} t}+\sum_{s} \alpha_{s g^{\prime} t} \leq \operatorname{Cap}_{g^{\prime}}-(1-d) * \operatorname{In}_{g^{\prime}(t-1)} \forall g^{\prime}, t \\
\sum_{g} \alpha_{g e^{\prime} t}+\sum_{e} \alpha_{e e^{\prime} t}+\sum_{s} \alpha_{s e^{\prime} t} \leq \operatorname{Cap}_{e^{\prime}}-\sum_{T}\left(1-d_{T}^{e^{\prime}}\right) * \operatorname{In}_{e^{\prime} t-1}^{T} \forall e^{\prime}, t \\
\sum_{g} \alpha_{g s^{\prime} t}+\sum_{e} \alpha_{e s^{\prime} t}+\sum_{s} \alpha_{s s^{\prime} t} \leq\left(\operatorname{Cap}_{s^{\prime}} * \sum_{q^{\prime}} U_{q^{\prime} s^{\prime}}\right)-\sum_{T}\left(1-d_{T}^{s^{\prime}}\right) * \operatorname{In}_{s^{\prime} t-1}^{T}
\end{gathered}
$$

Constraint (15) restricts the grains transported to godowns at stage II storage from any storage facility at stage I at a particular time point to be less than or equal to their residual capacity. The residual capacity is defined as capacity minus inventory carried over from the last period after deducting for grain loss during storage. Similarly, Constraints (16) and (17), restrict the transportation of grains to existing and new silos at stage II from any storage facility at stage I be less than their residual capacities determined by temperature points.

$$
\begin{aligned}
& \sum_{q^{\prime}} U_{q^{\prime} s^{\prime}} \leq 1 \quad \forall s^{\prime} \\
& \sum_{s^{\prime}} \sum_{q^{\prime}} U_{q^{\prime} s^{\prime}} \leq N^{\prime}
\end{aligned}
$$

Constraint (18) restricts that only one size of silo can be constructed at the potential site at stage II storage. Constraint (19) restricts the total number of silos constructed at stage II to maximum number of silos sanctioned to be constructed at that particular stage.

Inventory balance at producing states

$$
I n_{g t}=\sum_{m} \alpha_{m g p}-\sum_{g^{\prime}} \alpha_{g g^{\prime} t}-\sum_{e^{\prime}} \alpha_{g e^{\prime} t}-\sum_{s^{\prime}} \alpha_{g s^{\prime} t} \quad \forall T, \forall g, \forall t=1
$$




$$
\begin{gathered}
I n_{g t}=(1-d) * I n_{g(t-1)}-\sum_{g^{\prime}} \alpha_{g g^{\prime} t}-\sum_{e^{\prime}} \alpha_{g e^{\prime} t}-\sum_{s^{\prime}} \alpha_{g s^{\prime} t} \quad \forall g, \forall t \geq 2 \\
\sum_{T} I n_{e t}^{T}=\sum_{m} \alpha_{m e p}-\sum_{g^{\prime}} \alpha_{e g^{\prime} t}-\sum_{e^{\prime}} \alpha_{e e^{\prime} t}-\sum_{s^{\prime}} \alpha_{e s^{\prime} t} \quad \forall e, \forall t=1 \\
\sum_{T} I n_{e t}^{T}=\sum_{T}\left(1-d_{T}^{e}\right) * I n_{e t-1}^{T}-\sum_{g^{\prime}} \alpha_{e g^{\prime} t}-\sum_{e^{\prime}} \alpha_{e e^{\prime} t}-\sum_{s^{\prime}} \alpha_{e s^{\prime} t} \quad \forall e, \forall t \geq 2 \\
\sum_{T} I n_{s t}^{T}=\sum_{m} \alpha_{m s p}-\sum_{g^{\prime}} \alpha_{s g^{\prime} t}-\sum_{e^{\prime}} \alpha_{s e^{\prime} t}-\sum_{s^{\prime}} \alpha_{s s^{\prime} t} \quad \forall s, \forall t=1 \\
\sum_{T} I n_{s t}^{T}=\sum_{T}\left(1-d_{T}^{s}\right) * I n_{s t-1}^{T}-\sum_{g^{\prime}} \alpha_{s g^{\prime} t}-\sum_{e^{\prime}} \alpha_{s e^{\prime} t}-\sum_{s^{\prime}} \alpha_{s s^{\prime} t} \quad \forall s, \forall t \geq 2
\end{gathered}
$$

Constraint (20a) enforces that inventory level in a godown at stage I in time point $t=1$ is equal to the agricultural produce left after transporting to various storage facilities at stage II. Constraint (20b) shows the inventory balance at godown at stage I in subsequent time periods while accounting for the degradation happening on the inventory stored in the last time period.

Constraints (21a) and (21b) gives the inventory balance constraints for existing silos at stage I storage in first time period and subsequent periods after accounting for quality degradation. Similarly, constraints (22a) and (22b) provides the inventory balance constraints for new silo storage at stage I storage in first time period and subsequent periods after considering the quality degradation.

$$
\begin{gathered}
(1-d) * I n_{g^{\prime}(t-1)}+\sum_{g} \alpha_{g g^{\prime} t}+\sum_{e} \alpha_{e g^{\prime} t}+\sum_{s} \alpha_{s g^{\prime} t}=I n_{g^{\prime} t}+\sum_{r} \alpha_{g^{\prime} r t} \quad \forall g^{\prime}, t \\
\sum_{T}\left(1-d_{T}^{e^{\prime}}\right) * I_{e^{\prime} t-1}^{T}+\sum_{g} \alpha_{g e^{\prime} t}+\sum_{e} \alpha_{e e^{\prime} t}+\sum_{s} \alpha_{s e^{\prime} t}=\sum_{T} I n_{e^{\prime} t}^{T}+\sum_{r} \alpha_{e^{\prime} r t} \quad \forall e^{\prime}, t \\
\sum_{T}\left(1-d_{T}^{s^{\prime}}\right) * I n_{s^{\prime} t-1}^{T}+\sum_{g} \alpha_{g s^{\prime} t}+\sum_{e} \alpha_{e s^{\prime} t}+\sum_{s} \alpha_{s s^{\prime} t}=\sum_{T} I_{s^{\prime} t}^{T}+\sum_{r} \alpha_{s^{\prime} r t} \quad \forall s^{\prime}, t
\end{gathered}
$$

In a similar manner Constraints (23), (24) and (25) represents the inventory balance Equations for godowns, existing silos and new silos at stage II of the multi-echelon supply chain considering the quality degradation. The equations balance the existing inventory and the quantity received at any storage facility at stage II to quantity transported to the demand centres and the remaining inventory left at the storage facility

$$
\begin{gathered}
I n_{a t}^{T} \leq M * y_{a t}^{T} \quad \forall a=s, s^{\prime}, e, e \prime \\
\sum_{T} y_{a t}^{T}=1
\end{gathered}
$$

Constraints (26) and (27) enforce that the inventory at both stage I \& Stage II storage facilities can be stored only at one particular temperature in a given time point

$$
\sum_{g^{\prime}} \alpha_{g^{\prime} r t}+\sum_{e^{\prime}} \alpha_{e^{\prime} r t}+\sum_{s^{\prime}} \alpha_{s^{\prime} r t}=D_{r t} \quad \forall r, t
$$




$$
\begin{gathered}
\alpha_{s s^{\prime} t} \leq M * \sum_{q^{\prime}} U_{s^{\prime} q} \quad \forall s, s^{\prime}, t \\
\alpha_{s s^{\prime} t} \leq M * \sum_{q} U_{s q} \quad \forall s, s^{\prime}, t \\
\alpha_{m g}, \alpha_{m e}, \alpha_{m s} \text { are continuous variables } \forall m, g, e, s \\
U_{q s}, U_{q s^{\prime}} \in\{0,1\} \quad \forall q, s, s^{\prime}
\end{gathered}
$$

Constraint (28) ensures that the agricultural produce transported from the storage facilities at stage II storage to the retail centres meets the demand at respective retail points. Constraints (29) and (30) enforce that agricultural produce can be transported from any potential site at stage I to the potential site at stage II if these sites are selected for construction of storage facilities. Constraint (31) and (32) defines the continuous and binary nature of decision variables.

Objective functions

$$
\begin{gathered}
\text { Minimize(Total Cost) } Z_{1}=Z_{11}+Z_{12}+Z_{13}+Z_{14} \\
\text { Minimize(Total Inventory Holding Cost) } Z_{11}=\sum_{g^{\prime}} \sum_{t} H C_{g^{\prime} t} * I n_{g^{\prime} t} \\
+\sum_{e^{\prime}} \sum_{t} \sum_{T} H C_{e^{\prime} t}^{T} * I n_{e^{\prime} t}^{T}+\sum_{s^{\prime}} \sum_{t} \sum_{T} H C_{s^{\prime} t}^{T} * I n_{s^{\prime} t}^{T}+\sum_{g} \sum_{t} H C_{g t} * I n_{g t} \\
+\sum_{e} \sum_{t} \sum_{T} H C_{e t^{T}}^{T} * I n_{e t}^{T}+\sum_{s} \sum_{t} \sum_{T} H C_{s t^{2}}^{T} * n_{s t}^{T}
\end{gathered}
$$

Minimize cost of constructing infrastructure

$$
Z_{12}=\sum_{s}\left(\left(\sum_{q}\left(C C_{s q}+C R_{s} * R C_{s}\right) * U_{s q}\right)\right)+\sum_{s^{\prime}}\left(\left(\sum_{q}\left(C C_{s^{\prime} q}+C R_{s^{\prime}} * R C_{s^{\prime}}\right) * U_{s^{\prime} q}\right)\right)
$$

Minimize (Cost of Transportation from procurement centres to stage I storage)

$$
\begin{aligned}
Z_{13}= & \sum_{m} \sum_{g}\left(C T_{m g} * D S_{m g} * \alpha_{m g}\right)+\sum_{m} \sum_{e}\left(C T_{m e} * D S_{m e} * \alpha_{m e}\right) \\
& +\sum_{m} \sum_{s}\left(C T_{m s} * D S_{m s} * \alpha_{m s}\right)
\end{aligned}
$$

Minimize (Cost of Transportation from stage I to stage II storage and to retail points)

$$
Z_{14}=\left(\sum_{i} \sum_{j}\left(\left(T C R * P_{i j}\right)+T C T *\left(1-P_{i j}\right)\right) * D S_{i j} * \sum_{t} \alpha_{i j t}\right)
$$

where $i \in\left\{g+e+s+g^{\prime}+e^{\prime}+s^{\prime}\right\} j \in\left\{g^{\prime}+e^{\prime}+s^{\prime}+r\right\}$

Minimize the food quantity wasted due to quality degradation

$$
\begin{aligned}
Z_{2}= & \sum_{g} \sum_{t} d * I n_{g t-1}+\sum_{e} \sum_{t} \sum_{T}\left(d_{T}^{e}\right) * I n_{e t-1}^{T} \\
& +\sum_{s} \sum_{t} \sum_{T}\left(d_{T}^{s}\right) * I n_{s t-1}^{T}+\sum_{g^{\prime}} \sum_{t} d * I n_{g^{\prime} t-1}
\end{aligned}
$$




$$
+\sum_{e^{\prime}} \sum_{t} \sum_{T}\left(d_{T}^{e^{\prime}}\right) * \operatorname{In}_{e^{\prime} t-1}^{T}+\sum_{s^{\prime}} \sum_{t} \sum_{T}\left(d_{T}^{s^{\prime}}\right) * \operatorname{In}_{s^{\prime} t-1}^{T}
$$

Maximize network resilience

$$
Z_{3}=\sum_{s}\left(\left(\sum_{q} C_{s}^{*} * U_{s q}\right)\right)+\sum_{s^{\prime}}\left(\left(\sum_{q} C_{s^{\prime}}^{*} * U_{s^{\prime} q}\right)\right)
$$

Equation (33) represents the operational objective of minimizing the overall cost. The problem considers four major cost components which are described in Eqs. (33a-33d). Equation (33a) represents the total cost of storage in different storage facilities i.e. godowns, existing silos and the new silos at both stage I and stage II of the multi-echelon supply chain. Equation (33b) is the cost of constructing a new silo and also rail siding (if not present) in both at both stage I and stage II of the multi-echelon chain. Equation (33c) denotes the total cost of transportation from procurement centres to the stage I storage facilities. Equation (33d) denotes the total cost of transportation from stage I storage facilities to the stage II storage facilities in and then to the retail centres. The cost of transportation in this phase depends on the proportion of distances travelled by road and rail. Equation (34) shows the food quantity wasted due to the quality degradation at varying temperature points during different time periods. Equation (35) represents the strategic objective of maximizing network resilience while locating the sites for the construction of new silos both at in both stage I and stage II of the multi-echelon supply chains.

\subsubsection{Solution methodology}

The proposed problem for integrated procurement, storage and transportation in a multiechelon agri-food supply chain comprises of three objectives, i.e., cost minimization, wastage minimization and resilience maximization. These objectives are conflicting and incommensurable in nature. Since it is not possible to optimize all the objectives simultaneously, the integral part for solving the problem is to establish the trade-offs among these objectives in such a way that it captures the decision maker's perspective. Various methods are proposed in the literature to establish trade-offs among the objectives integrated with the search of alternatives for multi-objective decision making. The widely used approach is to present a set of pareto optimal solutions to the decision maker and then rank the solutions. This is generally achieved by eliciting their preferences and selecting the alternatives using appropriate MCDM methods. The other advanced methodologies integrated metaheuristics and MCDM methods to discard the poor solutions and further refine the solution space iteratively (Validi et al. 2020, 2021). The other set of approaches incorporate the trade-off among the objectives by providing rank order or weight of the objectives. These preferences are incorporated to form a scalar function combining all the objective functions (Chiandussi et al. 2012). Here the decision maker is not presented with a set of pareto optimal solution but the final solution is obtained directly. The main advantages of this method include simplicity and efficiency in implementation. However, the biggest challenge in this methodology is to obtain criteria weights and appropriate scaling of the objectives.

In this paper, fuzzy set theory is used to obtain the desirable solution in multiple objective optimization. Fuzzy set theory has proved to offer several distinct advantages as a basis for multi objective optimization by searching for some optimal options which "best satisfy most of the important objectives" and differ significantly from the traditional notion to try to find an optimal option which best satisfies "all the objectives". This approach also captures the notion of satisfaction of objective functions for different decision alternatives (Carlson and 
Fuller 1994). The satisfaction value/achievement of an objective with respect to a decision is defined as a membership function with the help of a fuzzy set. The membership function for a maximization objective is formulated as follows:

$$
\mu_{\mathrm{Z}}(\mathrm{z} 1)= \begin{cases}0, & z 1<\mathrm{N}_{\mathrm{L}} \\ \frac{\mathrm{z} 1-\mathrm{N}_{\mathrm{L}}}{\mathrm{N}_{\mathrm{U}}-\mathrm{N}_{\mathrm{L}},} & \mathrm{N}_{\mathrm{L}} \leq z 1<\mathrm{N}_{\mathrm{U}} \\ 1, & z 1 \geq \mathrm{N}_{\mathrm{U}}\end{cases}
$$

In Eq. (36), for an objective function " $z$ " (maximization nature), if the objective value $\mathrm{z}=\mathrm{z} 1$ is greater than equal to " $\mathrm{N}_{\mathrm{U}}$ ", $\mathrm{DM}$ will be fully satisfied for $\mathrm{z}\left(\mu_{\mathrm{z}}(\mathrm{z} 1)=1\right)$. The satisfaction level decreases linearly when the objective function value decreases from $\mathrm{N}_{U}$ to $\mathrm{N}_{\mathrm{L}}$ and becomes zero if it falls below $\mathrm{N}_{\mathrm{L}}$.

For the objective function ' $z$ ' that are of minimization type, membership function of the goal is defined as follows:

$$
\mu_{\mathrm{z}}(\mathrm{z} 1)= \begin{cases}1, & z 1 \leq \mathrm{N}_{\mathrm{L}} \\ \mathrm{N}_{\mathrm{U}}-\mathrm{z} 1 & \mathrm{~N}_{\mathrm{L}} \leq z 1<\mathrm{N}_{\mathrm{U}} \\ 0, & z 1 \geq \mathrm{N}_{\mathrm{U}}\end{cases}
$$

In Eq. (37), for an objective function " $\mathrm{z}$ " (minimization nature), if the objective value $\mathrm{z}=$ $\mathrm{z} 1$ is less than equal to " $\mathrm{N}_{\mathrm{L}}$ ", DM will be fully satisfied for $\mathrm{z}\left(\mu_{\mathrm{z}}(\mathrm{z} 1)=1\right)$. The satisfaction level decreases linearly when the objective function value increases from $N_{L}$ to $N_{U}$ and becomes zero if it is above $\mathrm{N}_{\mathrm{U}}$.

The bounds of the membership function $\mathrm{N}_{\mathrm{L}}, \mathrm{N}_{\mathrm{U}}$ be identified by obtaining ideal, non-ideal solutions of each objective function (Zimmermann, 1978) or it can also be defined through targets defined by DM in linguistic terms (Gupta \& Mohanty, 2015).

This approach handles the problem of incommensurability and different satisfaction at varying level of multiple objectives effectively. The second problem pertains to aggregation of multiple membership functions to obtain the overall objective function for the decision. The membership functions corresponding to multiple objectives needs to be aggregated to obtain a single objective function. There exist multiple fuzzy aggregation operators to combine the membership functions and arrive at overall decision function. Induced Ordered Weighted Averaging (IOWA), an aggregation operator, is used which combines the three membership functions and attaches the weights corresponding to the specified priority levels. The priority attached with different objective functions may vary depending on the context of the problem. The important dimensions of the operator are given below:

The IOWA operator is a k-dimensional function as defined below (Yager, 2003):

$$
\text { IOWA: }[0,1]^{k} \rightarrow[0,1] ; \text { IOWA }:\left(<u_{1,} x_{1}><u_{2}, x_{2}>, \ldots \ldots,<u_{k}, x_{k}>\right)=\sum_{j=1}^{k} w_{j} b_{j}
$$

where $X=\left[x_{1}, x_{2} \ldots x_{k}\right]$ are $\mathrm{k}$ values to be aggregated. The vector $U=\left[u_{1} \ldots u_{k}\right]$ is the order inducing vector whose magnitudes define the order in which the elements of $X$ to be aggregated; specifically, $B_{U}=\left[b_{1}, b_{2} \ldots b_{k}\right]$ is the argument vector $\mathrm{X}$ reordered according to the magnitude of $u_{i}^{\prime} s$ so that $b_{i}$ is the $\mathrm{x}$ having associated with it the $i$ th largest among the values $u_{1}, u_{2} \ldots u_{k}$.

When multiple satisfaction levels are aggregated, it could be done based on different principles such as a decision should meet "all", "most important", "at least a few" "almost all" objectives. These linguistically expressed aggregation principles gives insight into DM's 
implicit evaluation framework and thus should be accounted for in the overall decision function. The concept of linguistic quantifiers is applied to compute the weights based on the linguistically expressed aggregation principle (Chiclana et al. 2007; Yager, 1993). The quantifier guided aggregation, corresponding to the "most", denoted as $Q(r)=\sqrt{ } \mathrm{r}$ gives a procedure to evaluate the overall satisfaction of most important criteria by the alternative $\mathrm{x}$.

The weighting vector $\mathrm{W}=\left[\mathrm{w}_{1}, \mathrm{w}_{2}, \ldots, \mathrm{w}_{\mathrm{s}}\right]$ associated with the IOWA operator to aggregate "s" values is computed using a linguistic quantifier function from Eq. (38) below.

$$
w_{i}=Q\left(\frac{i}{s}\right)-Q\left(\frac{i-1}{s}\right) \text { for } i=1,2 \ldots s .
$$

Example: Lets assume, there are three values $X=[0.1,0.3,0.8]$ with the order of importance denoted by vector $U=[3,8,6]$ are to be aggregated such that the aggregated value reflect the satisfaction of the "most important" objectives. For $\mathrm{s}=3$ values to be aggregated, the weight to the arguments (in the order of their importance) is assigned as

$$
\begin{aligned}
& w_{1}=Q\left(\frac{1}{3}\right)-Q\left(\frac{1-1}{3}\right)=\sqrt{1 / 3}-\sqrt{0}=0.57 \\
& w_{2}=Q\left(\frac{2}{3}\right)-Q\left(\frac{2-1}{3}\right)=\sqrt{2 / 3}-\sqrt{1 / 3}=0.24 \\
& w_{1}=Q\left(\frac{3}{3}\right)-Q\left(\frac{3-1}{3}\right)=\sqrt{3 / 3}-\sqrt{2 / 3}=0.19
\end{aligned}
$$

With these weights $[0.57,0.24,0.19]$, the aggregated value of $X=[0.1,0.3,0.8]$ is obtained as IOWA: $(<3,0.1>,<8,0.3>,<6,0.8>)=0.57 * 0.3+0.24 * 0.8+0.19 * 0.1=0.382$. It is to be noted that the largest weight is assigned to the argument " 0.3 " which has the highest priority.

The priority order of different objectives for the proposed problem is taken as Cost Minimization, Wastage Minimization and Resilience Maximization. The aggregation of the goals via their membership values is shown in Eq. (39) below.

$$
\begin{aligned}
& \operatorname{Max}\left(I O W A:\left(\left\langle u_{\text {cost }}, \mu_{\text {cost }}\right\rangle,\left\langle u_{\text {wastage }}, \mu_{\text {wastage }}\right\rangle,\left\langle u_{\text {Resilience }}, \mu_{\text {Resilience }}\right\rangle\right)\right) \\
& =\operatorname{Max}\left(0.57 * \mu_{\text {cost }}+0.24 * u_{\text {Resilience }}+0.19 * \mu_{\text {wastage }}\right)
\end{aligned}
$$

Subject to the constraints

$$
\mu_{\text {cost }}, \mu_{\text {wastage }}, \mu_{\text {Resilience }} \leq 1
$$

\section{Case study of public distribution system in India}

India made significant improvement in food grain production from 50 million tonnes in 1950-51 to about 250 million tonnes (MT) in 2014-15 transitioning from a beneficiary of food aid from other countries to a net food exporter (United Nations). However, India still struggles to ensure food availability for all and curb the hunger for its 190 million people (Tanksale \& Jha, 2016; IFPRI, 2017). The Food Corporation of India (FCI), a nodal agency for the implementation of PDS, deals with the procurement, storage, movement and distribution of food grains to the beneficiaries with the help of central and state governments (Balani, 2013). According to the CAG report (CAG, 2013 report), India's grain production and consequently procurement by FCI has increased manifold to commensurate with the growing demands of the country. In year 2018-19, the total procurement of wheat by Food Corporation of India 
(FCI) was 357 lakh metric tonnes (LMT) which was significantly higher than the available storage capacity. But due to the issues of inefficiencies in PDS supply chain and post-harvest losses during storage and transportation, the food availability for all is a major concern (Irani et al. 2018). One major challenge is the lack of proper storage infrastructure in both grain producing and grain consuming states (Tanksale \& Jha, 2015). It has been repeatedly reported by CAG that FCI's storage capacity is alarmingly low in comparison to the increased stock of grains procured in order to meet the growing consumption caused by the steady increase in population. According to Food and Agricultural Organization (FAO), food grains worth $\$ 14$ billion is damaged in India annually. Moreover, it has also been observed that a large part of existing infrastructure is not able to protect the food grains from moisture, heat, insects or rodents. One of the critical factors in grain quality deterioration is inappropriate temperature conditions leading to the grain respiration that renders a part of stored grains unfit for human consumption. In India, 20-30\% of total spoilage occurs at the storage stage. The post-harvest losses are estimated to be 12 to 16 million metric tonnes every year. The World Bank stipulates that this amount is sufficient to feed one third of the poor population of the country (Sharon et al. 2014).

Climate change and other global crisis often add to the complexity of the problem and challenges the grain distribution across the country (Maiyar et al., 2017). For Instance, in year 2015, million tonnes of food grains are spoiled at the storage facilities due to flooding and rains. Since the storage infrastructure is needed, the sites locations must be strategically located in such a manner that overall network resilience is enhanced. The storage facilities must not only provide safe storage during these calamities but also be easily accessible to other units of the supply chain. The other factors pertaining to ease of operations and maintenance should be considered to minimise the food loss, transportation and rental costs and enable efficient distribution in the event of occurrence of any natural disaster or calamity. Also, the new storage infrastructure at different stages of PDS supply chain must be temperaturecontrolled to ensure better preservation and reduce food losses.

To address this problem, the proposed FMOLP is used. The problem considers 8 procurement centres $\left(M_{1}, M_{2}, \ldots M_{8}\right), 5$ godowns $\left(G_{1}, G_{2}, \ldots G_{5}\right), 4$ existing silos $\left(E_{1}, E_{2}, \ldots E_{4}\right)$ in the producing states (Stage I storage). Similarly, in the consuming state (stage II storage), there are 7 godowns $\left(G D_{1}, G D_{2}, \ldots G D_{7}\right)$ and 5 existing silos $\left(E S_{1}, E S_{2}, \ldots E S_{5}\right)$. In the event of inadequate storage capacity at producing or consuming states, new silos can be constructed at 8 potential sites $\left(N_{1}, N_{2}, \ldots N_{8}\right),\left(F_{1}, F_{2}, \ldots F_{8}\right)$ in producing and consuming states respectively. The silos (both existing and new) have the facility of storing in temperature controlled environment ranging from temperature $T P_{1}, T P_{2}, \ldots T P_{5}$. The cost of storage decreases with the increase in temperature from $T P_{1}$ to $T P_{5}$. On each site, there is a possibility to construct three different sizes of grain silos- small, medium and large having different capacities. From consuming state storage facilities, the grains are distributed to 7 retail points. The problem is solved for a planning horizon of 6 time periods $\left(T_{1}, T_{2} \ldots T_{6}\right)$. The problem considers the distances between procurement centres and various storage facilities, capacities, cost of holding, handling, transportation and construction of new silos are provided in Appendix B1. The cost of transportation from producing to consuming states depend on the proportion of distance covered by rail and road respectively. The proportion and distance between various nodes are assumed to be known. The quantity demanded at demand centres, quantity available with producing states, cost of transportation, holding, construction cost and respective capacities of storage facilities are also known and are provided in Appendix B2. The data used for numerical illustration has the characteristics of actual bulk grain movement taken from the website of Food Cooperation of India. The FCI managers, site experts and risk analysts evaluate the potential sites for silo construction in both producing and consuming states 
Table 3 Resilience scores for potential sites in producing and consuming states

\begin{tabular}{llllllll}
\hline & Si* & Si- & Resilience index & & Si* & Si- & Resilience index \\
\hline$N_{1}$ & 0.732219 & 1.027392 & 0.583874 & $F_{1}$ & 0.76478 & 0.485559 & 0.388342 \\
$N_{2}$ & 1.049884 & 0.479172 & 0.313378 & $F_{2}$ & 0.40247 & 0.902356 & 0.691553 \\
$N_{3}$ & 1.090826 & 0.676341 & 0.382726 & $F_{3}$ & 0.750641 & 0.534418 & 0.41587 \\
$N_{4}$ & 0.727784 & 0.912724 & 0.556367 & $F_{4}$ & 0.80125 & 0.536426 & 0.401013 \\
$N_{5}$ & 0.830363 & 0.835243 & 0.501465 & $F_{5}$ & 0.520625 & 0.796719 & 0.604792 \\
$N_{6}$ & 0.987807 & 0.711788 & 0.418799 & $F_{6}$ & 0.748757 & 0.481171 & 0.391219 \\
$N_{7}$ & 1.025398 & 0.701392 & 0.406182 & $F_{7}$ & 0.831925 & 0.401202 & 0.325353 \\
$N_{8}$ & 0.991752 & 0.632698 & 0.389485 & $F_{8}$ & 0.439424 & 0.89989 & 0.671904 \\
\hline
\end{tabular}

on eight different criteria as discussed in Table 2. The new silos locations at the producing states $(\mathrm{N} 1, \ldots \mathrm{N} 8)$ and $(\mathrm{F} 1, \ldots \mathrm{F} 8)$ are evaluated on the eight criteria as shown in the first table of Appendices A1, A2. The criterion C1 'Availability of rail siding" is evaluated as $\{0,1\}$ indicating absence presence of the siding at a location. The criteria $\mathrm{C} 2-\mathrm{C} 8$ are assessed on the scale (1-9) denoting satisfaction of a criterion in a location. For simplicity, equal weights are assigned to eight criteria. The resilience score obtained for both producing and consuming states. are shown in Table 3. The detailed steps for the calculation of resilience score using TOPSIS are provided in appendices (A1, A2).

These resilience scores of the potential sites become an input to the FMOLP wherein one objective is to maximize the overall network resilience. The proposed FMOLP is solved using the solution methodology discussed in Sect. 3.4. In order to arrive at the membership functions for maximizing and minimizing goals, the lower and upper bounds obtained by solving the FMOLP with optimizing one objective at a time. The objective function values obtained while optimizing a single objective is given in Table 7 below where the ideal objective function values are boldfaced.

Using Eq. 36, the membership function of resilience maximization with the bounds 1.39, $2.53)$ is shown below:

$$
\mu_{\operatorname{Res}}(\operatorname{Res})=\left\{\begin{array}{l}
0, \text { Res }<1.399255 \\
\frac{\operatorname{Res}-1.399}{\mathrm{~N}_{\mathrm{gU}}-1.399255}, 1.399255 \leq \text { Res }<2.533 \\
1, \text { Res } \geq 2.533
\end{array}\right.
$$

Table 4 Ideal objective function values

\begin{tabular}{lclc}
\hline & Cost minimization & Food loss minimization & Resilience maximization \\
\hline Cost & $\mathbf{5 6 2 , 4 2 9 , 9 0 0 . 0 0}$ & $1.08 \mathrm{E}+09$ & $1,301,106,000.00$ \\
Food loss & 604.5863 & $\mathbf{1 6 7}$ & 392.347 \\
Resilience & 1.399255 & 2.094 & $\mathbf{2 . 5 3 3}$ \\
\hline
\end{tabular}

Bold values represent the ideal objective function value for each objective alone 
Similarly, using Eq. 37, membership functions for cost $\mu_{\text {Cost }}$ and food loss $\mu_{\text {Loss }}$ are given below:

$$
\begin{gathered}
\mu_{\text {Cost }}(\text { Cost })= \begin{cases}0, & \text { Cost } \geq 1301106000.00 \\
\frac{1301106000.00-\text { Cost }}{1301106000.00-562429900}, & 562429900 \leq \text { Cost }<1301106000.00 \\
1, & \text { Cost } \leq 562429900\end{cases} \\
\mu_{\text {loss }}(\text { Loss })= \begin{cases}0, & \text { Loss } \geq 604.5863 \\
\frac{604.5863-\text { Loss }}{604.5863-167}, & 167 \leq \text { Loss }<604.5863 \\
1, & \text { Loss } \leq 167\end{cases}
\end{gathered}
$$

Using Eq 39, the above membership functions are combined to obtain the objective for FMOLP as follows:

$$
Z=\operatorname{Max}\left(0.57 * \mu_{\text {cost }}+0.24 * u_{\text {Resilience }}+0.19 * \mu_{\text {Loss }}\right)
$$

After solving FMOLP with the above single objective function obtained as aggregation of membership functions of different objective functions, the resultant decision led to the cost $=$ $628,980,400$, res $=1.84$ and wastage $=168.2897$ which achieved the satisfaction of 0.909 , 0.997 and 0.397 respectively in the aspirations of decision makers. The result obtained are discussed below.

In Fig. 3, the grain procured from the procurement centres during the harvest season is shown It can be seen from Fig. 3 that two new silos at location $\mathrm{N}_{4}$ and $\mathrm{N}_{6}$ needs to be constructed in producing states. The capacity would be 200 thousand Metric Tonnes (TMT) for both the silos. It can be seen that out of total grain procured at mandi M1 i.e. 400 TMT, 60 TMT are stored at godown $\mathrm{G}_{1}, 200$ TMT are stored at godown $\mathrm{G}_{3}$ and 140 TMT are stored in existing silo E3. Figure 4 shows the optimized quantities transported from the three kinds of storage facilities at producing states to the storage facilities in consuming states over a planning horizon of six months. It can also be seen from the Fig. 4 that five new silos are being constructed in consuming states at locations $F_{2}, F_{3} F_{6} F_{7}$ and $F_{8}$. Figure 5 shows the quantity of grains transported from the storage facilities in consuming states to the demand centres located in consuming states over the planning period of six months. The detailed solution is provided in appendix Tables $\mathrm{C} 1, \mathrm{C} 2$ and $\mathrm{C} 3$.

The diagrammatic representation of the flow of grains from one location to another in the supply chain of PDS is given in Fig. 6 below. The different modes of transportation i.e. rail or rod or combined are shown with different kinds of arcs.

\section{Computational experiments}

In this section, the detailed computational experimentation is carried out using various problem instances and results are studied. Three problem categories: small, medium and large-sized are considered to investigate the efficiency of the developed model and analyse trade-offs among three conflicting objectives. The problem sizes are defined based on the number of procurement centres, stage-I storage facilities, stage II storage facilities, retail points and time periods in the planning horizon. The data generated for these experiments is benchmarked with several reliable secondary sources such as PDS portals of India, Ministry of Consumer Affairs, Food and Public Distribution. Table 5 presents the problem sizes in terms of the various components of PDS. Further, range of the problem parameters are provided in Table 6. Table 7 provides the comprehensive description of each type of problem 
Procurement Centre 1

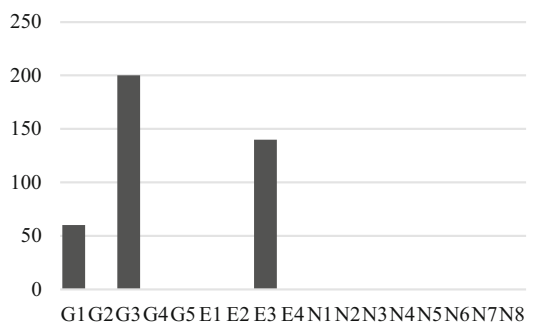

Procurement Centre 3

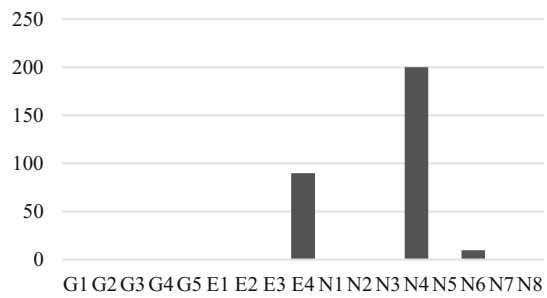

Procurement Centre 5

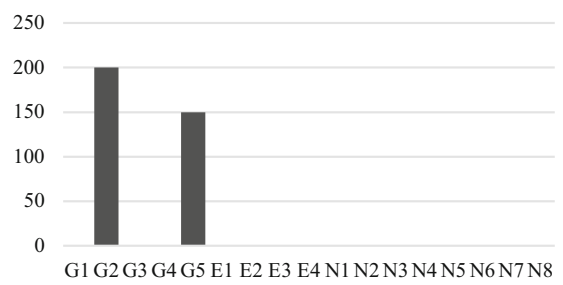

Procurement Centre 7

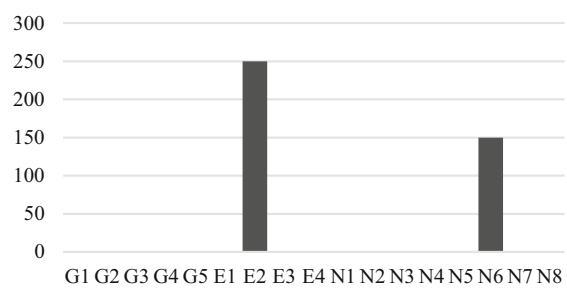

Procurement Centre 2

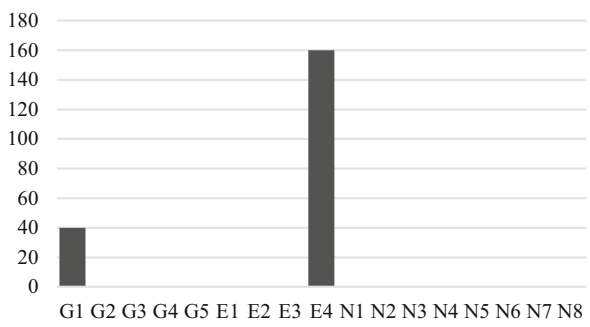

Procurement Centre 4

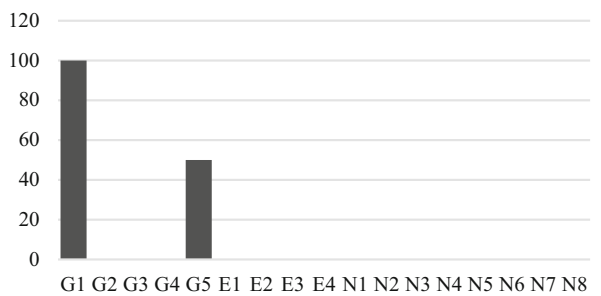

Procurement Centre 6

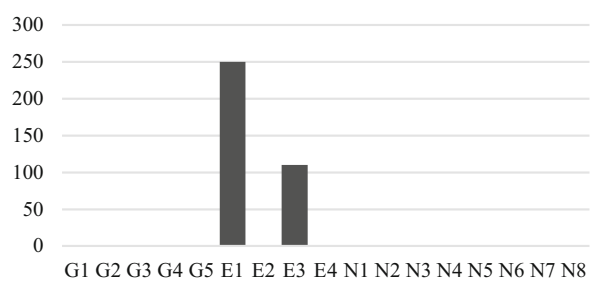

Procurement Centre 8

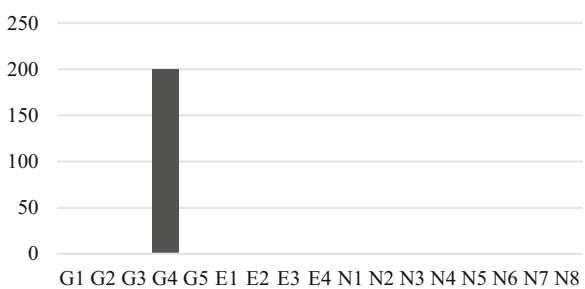

Fig. 3 Optimal storage and grain movement from procurement centres to stage I storage in producing states

instance along with the total number of decision variables and constraints in corresponding formulations.

Table 8 summarizes the objective function values obtained when the FMOLP is solved by optimizing one of the objectives. The ideal values for each objective are shown in boldface. It can be shown that the results differ across different instances. In order to understand the trade-offs between the three criteria, satisfaction levels of different objectives are obtained as shown in Eqs. (36) and (37). For example, in the first problem of small size 


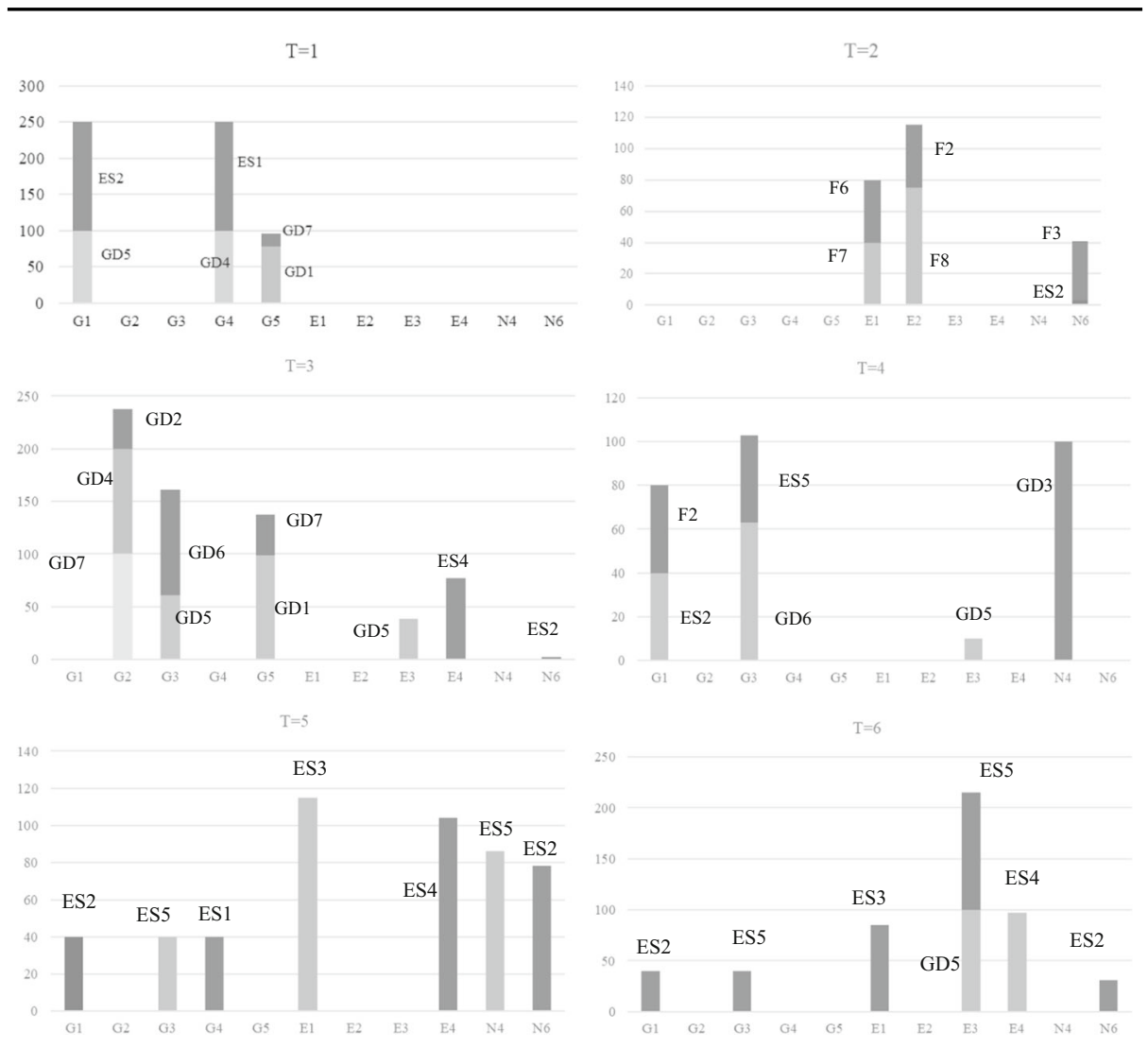

Fig. 4 Optimal distribution of grains from producing to consuming states

category, satisfaction level of decision maker for the wastage $=347.172$ is obtained as $(461.5957-347.172) /(461.5957-321.79)=0.814$ when the cost is optimized. As shown in Fig. 7 (top left), when the decision is taken with a single objective of cost optimization, very less satisfaction in the range $[0,0.35]$ is achieved in other two objectives. This gives evidence of the extent to which economic considerations conflict with food wastage and resilience objectives. Further, this validates the reason for the application of fuzzy multiple objective technique to arrive at a solution that achieves satisfaction in all the objectives to a reasonable level.

The numerical experiments validated that our methodology helps us in arriving a solution with the satisfaction level in the range of $[0.8,1]$ as shown in Fig. 7 (bottom right).

The classic problem of network design optimization in supply chain is known to be NPhard (Allaoui et al. 2018). Since the problem studied in this paper integrates both strategic and operational aspects of agri-food supply chain, it's also NP-hard. To get some idea on the computation time, the average computation time for three problem categories are given in the Table 9 below.

Though the problem instances considered in this analysis are solved within a reasonable time but it was observed that computing time can significantly increase when problem size is further increased. The categories have been defined based on the number of nodes in the supply chain network and thus impact the number of decision variables and constraints in the 


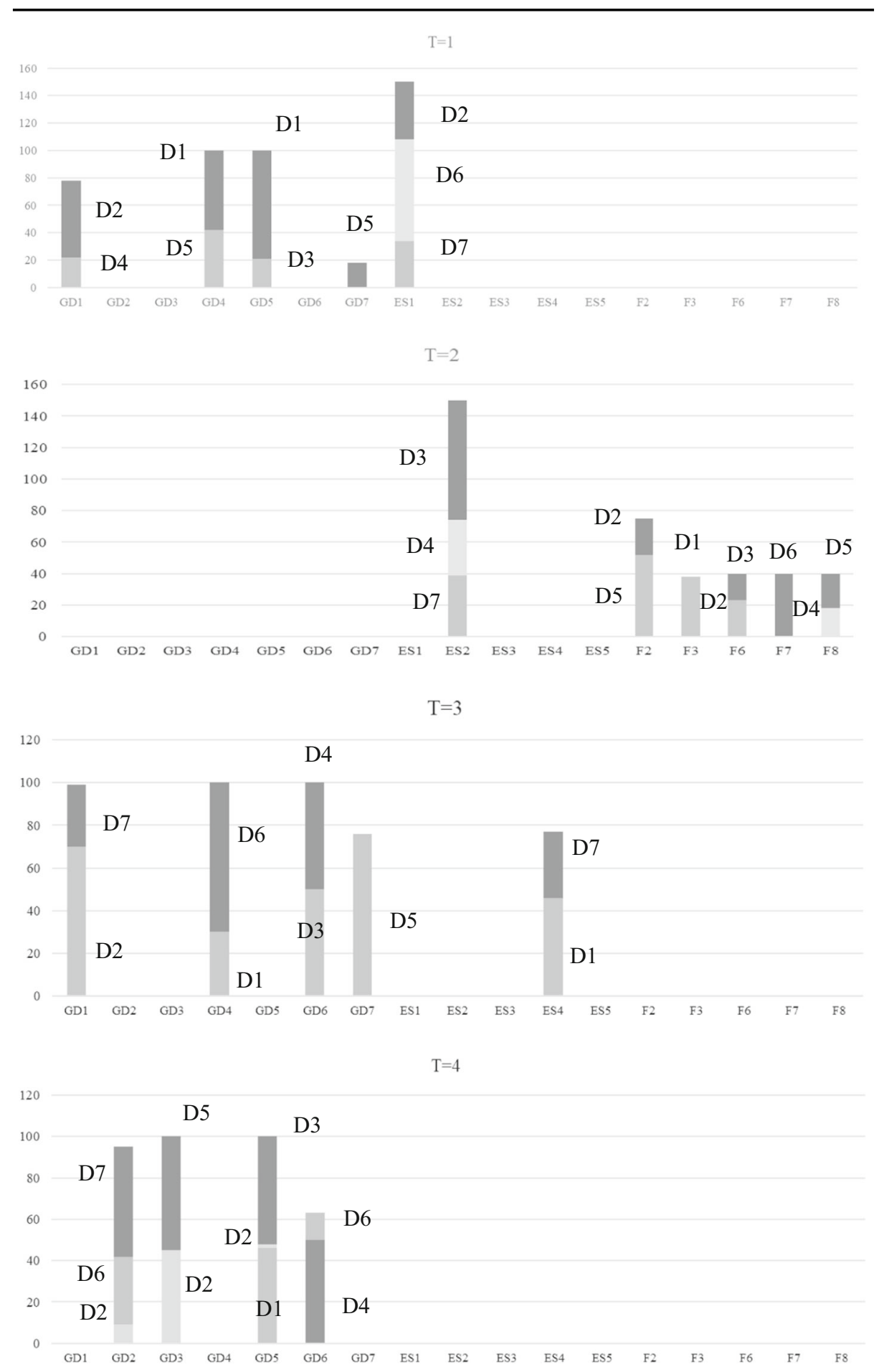

Fig. 5 Optimal quantity transported from storage facilities in consuming states to demand centres 


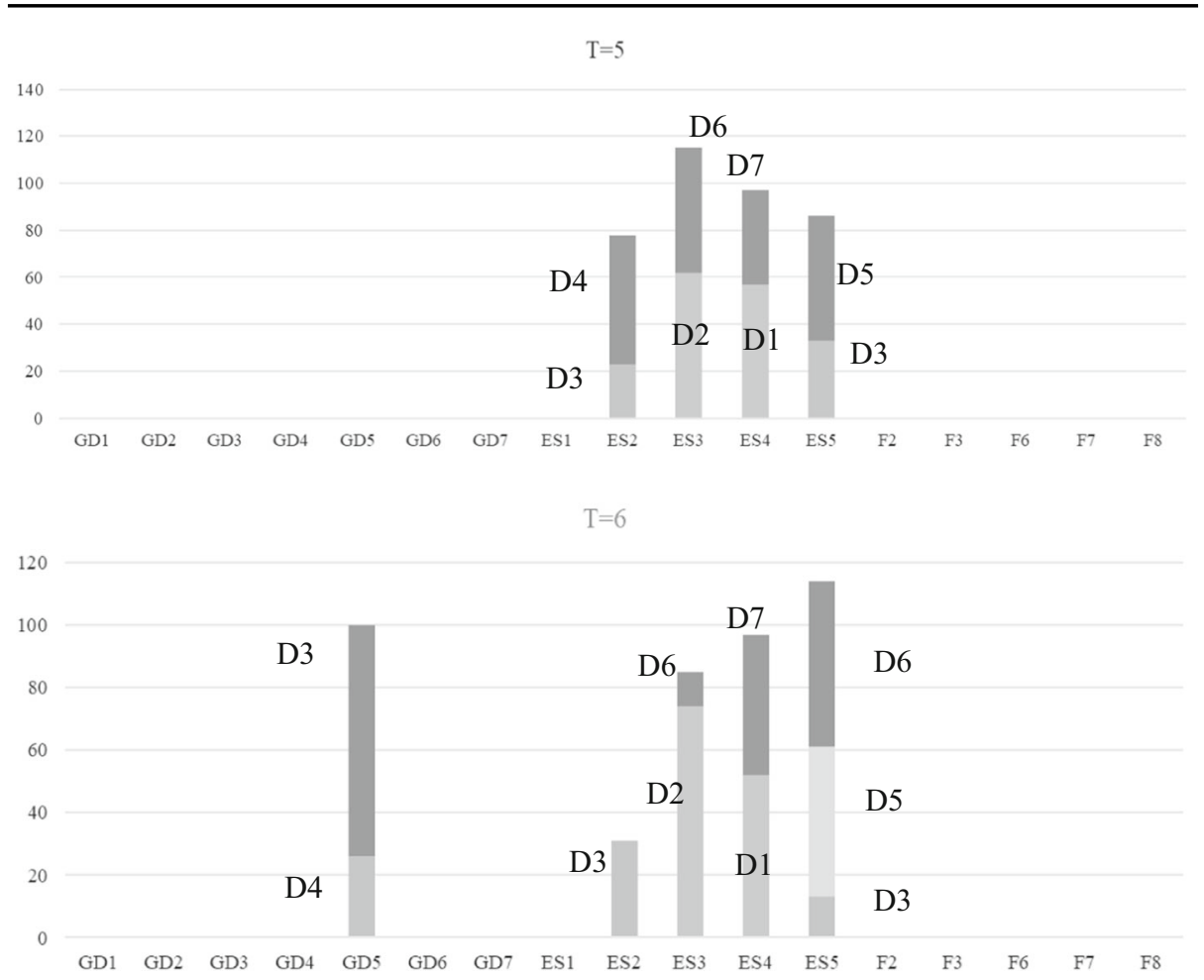

Fig. 5 continued

problem. Therefore, the computational time could become exorbitant with a problem with higher dimension (Maffioli \& Galbiati, 2000). There are various approaches to deal with the NP-hardness of the optimization problem which can be used for the problems of large size such as constraint programming (Galinier et al. 2011), machine learning algorithms (Guo et al., 2007) and meta heuristic methods (Janiak et al. 2013).

\section{Implications and theoretical contributions}

The following are the key managerial and theoretical contributions proposed in this study:

\subsection{Managerial implications}

The proposed FMOLP can help decision makers to integrate the decisions regarding procurement, storage and transportation in a multi-echelon supply chain. This improves the coordination among different stages of the supply chain and improves the overall operational cost and reduces the food wastage. The proposed model can also help decision makers to identify the lack of storage infrastructure at different stages of agri-food supply chain. The framework also provides decision makers with a framework to identify the resilient sites for constructing storage infrastructure that simultaneously minimizes operating cost and 


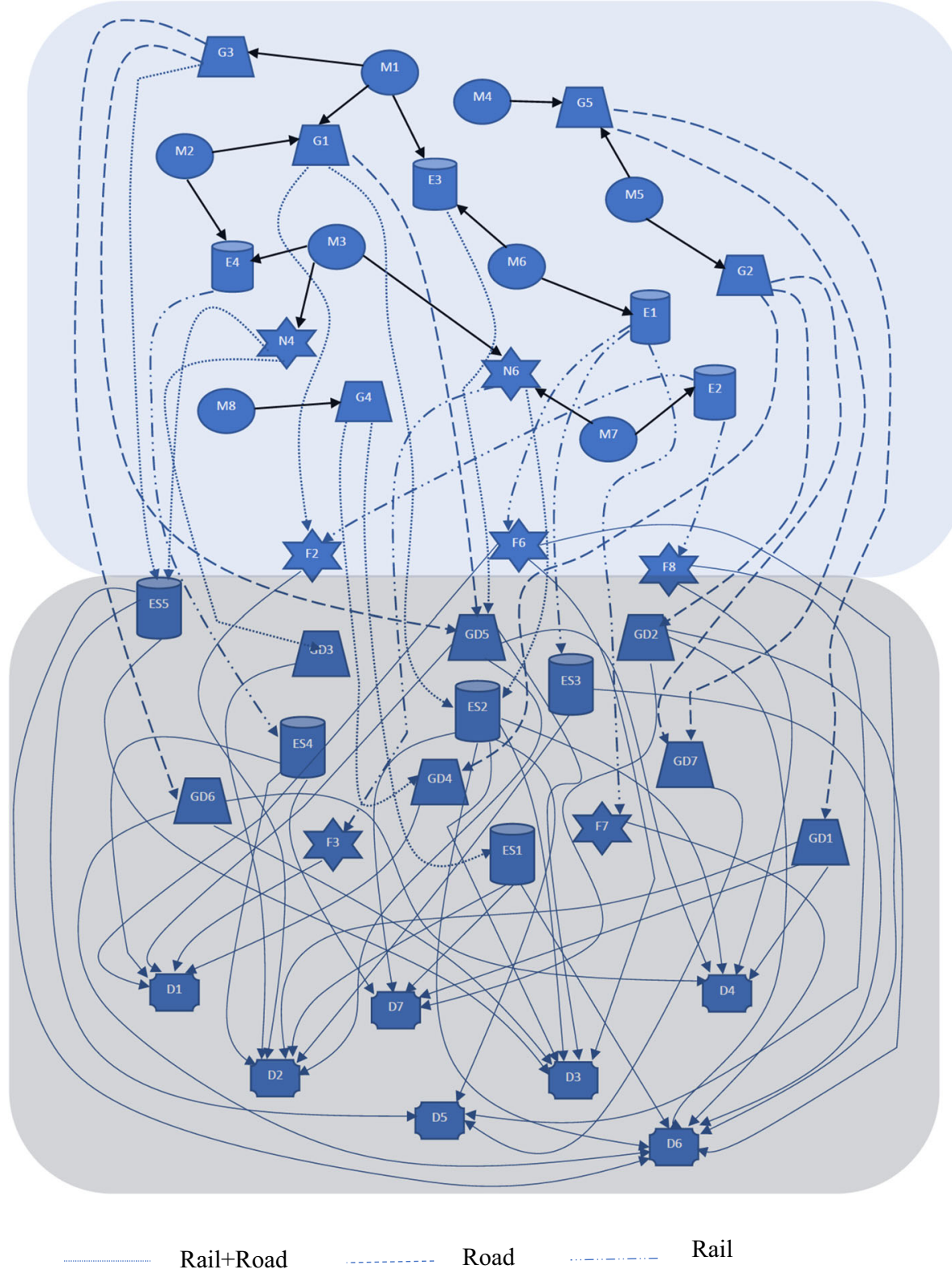

Fig. 6 The graphical representation of the solution obtained

food wastage in the network and maximizes the network resilience. This study also establishes the relationship between the storage temperature and the food quality degradation and can help the decision makers to account for the food loss at various storage facilities and deciding on the optimal storage temperature. Through the proposed model, three conflicting 


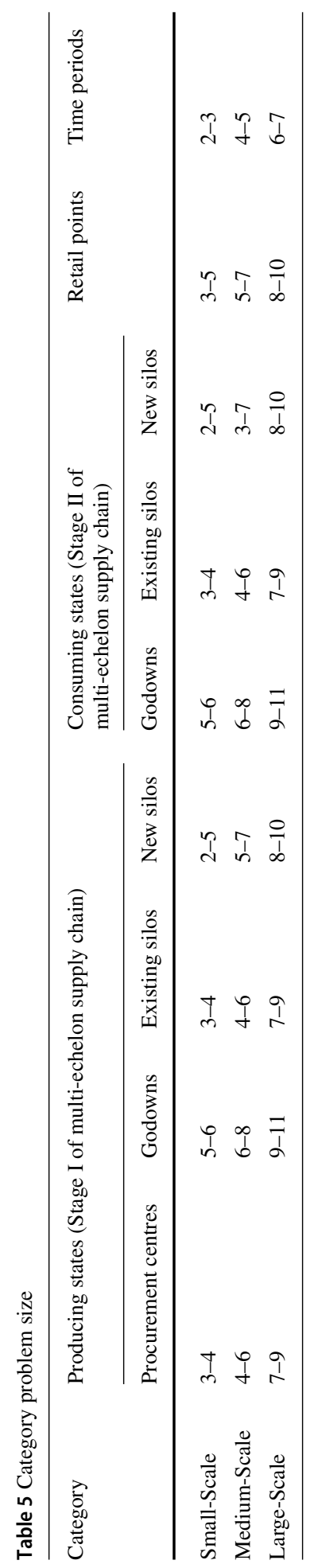


Table 6 The values of input parameters of the model

\begin{tabular}{llll}
\hline Parameters & Range of values & Parameters & Range of values \\
\hline Capg & 250 & $P_{i j}$ & $0-1$ \\
Cap $_{e}$ & 300 & $d_{i j}$ & $200-1000$ \\
$G P_{m}$ & $200-1000$ & $H C_{g t}$ & $2-5$ \\
$C C_{s q}$ & $30,000,000-50,000,000$ & $H C_{e t}^{T}$ & $2-5$ \\
$C C_{s^{\prime} q}$ & $250,300,350$ & $H C_{s t}^{T}$ & $2-5$ \\
$C R_{s}$ & $5,000,000$ & $H C_{g^{\prime} t}$ & 5 \\
$C T_{m g}$ & $5-10$ & $H C_{e^{\prime} t}^{T}$ & Increase from 5 to 10 with a unit decrease in \\
& & $H C_{s^{\prime} t}^{T}$ & temperature \\
$C T_{m e}$ & $5-10$ & $D$ & Increase from 5 to 10 with a unit decrease in \\
$C T_{m s}$ & $5-10$ & $d_{T}^{e}$ & temperature \\
$D S_{m g}$ & $40-100$ & $d_{T}^{s}$ & Decrease from 5 to $1 \%$ with unit decrease in \\
& & & temperature \\
$D S_{m e}$ & $50-120$ & $d_{T}^{e^{\prime}}$ & Decrease from 5 to $1 \%$ with unit decrease in \\
& & & Decrease from 5 to $1 \%$ with unit decrease in \\
$D S_{m s}$ & $80-150$ & $d_{T}^{s^{\prime}}$ & temperature \\
$R P s$ & 0,1 & $C_{s}^{*}$ & Decrease from 5 to $1 \%$ with unit decrease in \\
& & $C_{s^{\prime}}^{*}$ & temperature \\
$R C s$ & 0,1 & & {$[0.2,0.8]$} \\
$T C R$ & 30 & &
\end{tabular}

concerns of decision maker-minimizing cost, reducing quality degradation and maximizing site resilience are jointly addressed. The computational experimentation conducted for different problem sizes (small, medium \& large) investigate the efficiency and robustness of the proposed FMOLP and analyse the trade-off among three conflicting objectives. The fuzzy goal programming-based solution approach used in the paper provides a well-regarded framework to incorporate aspirations of the decision maker. This helps decision makers to understand the trade-offs between the operational and strategic objectives in the system and consider the important aspects of quality and resilience into the storage and distribution of food rather than only making cost centric decisions.

\subsection{Theoretical contributions}

The proposed FMOLP in this paper contributes to the literature by simultaneously addressing the operational objectives of overall operational cost minimization and food loss reduction and the long-term strategic objective of maximizing network resilience in a single framework. There is a limited work done on modelling resilience into agri-food supply chain networks. To address this, the paper proposes a framework to evaluate the need for improving the storage infrastructure and evaluate the resilience score of each potential site for construction of storage infrastructure at different stages of the supply chain. The paper also proposes 


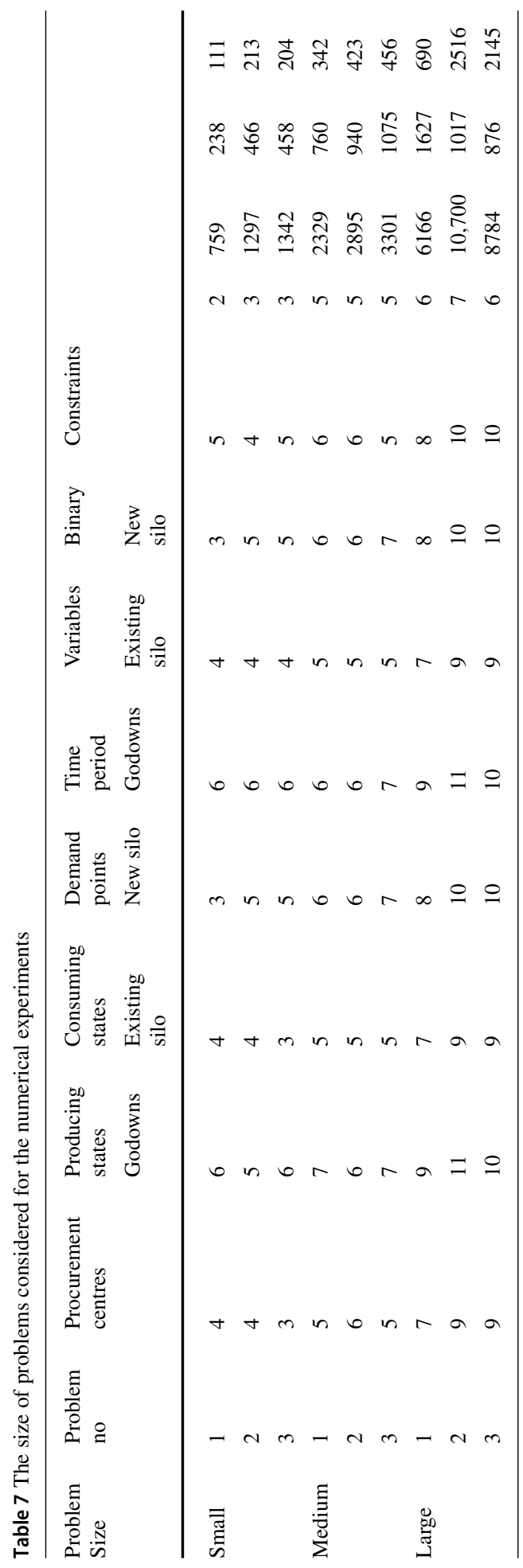




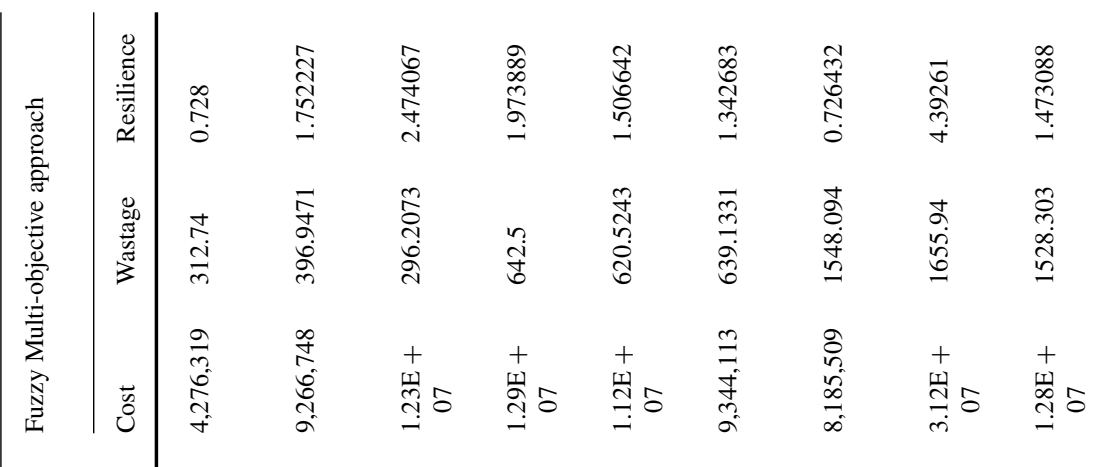

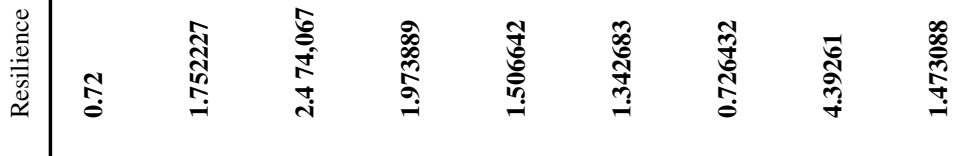

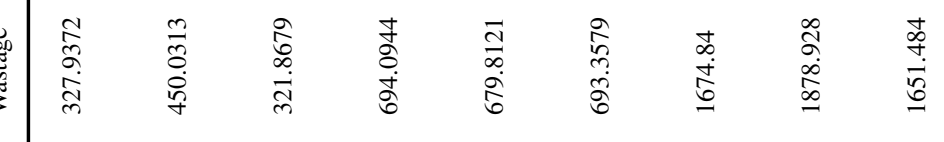

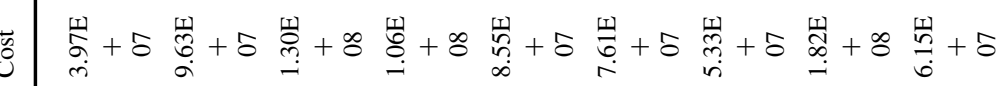

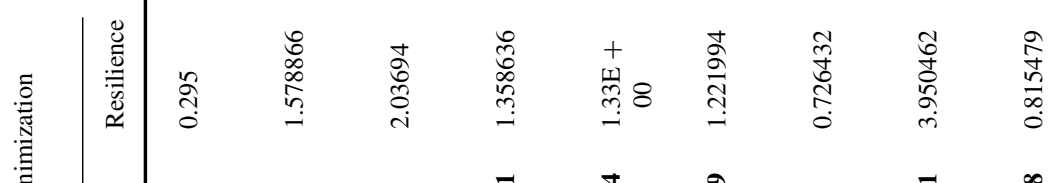

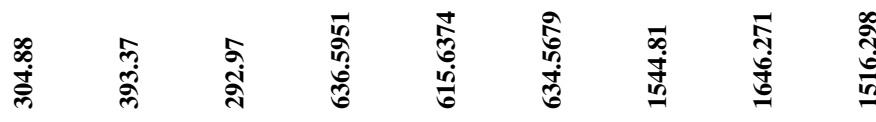

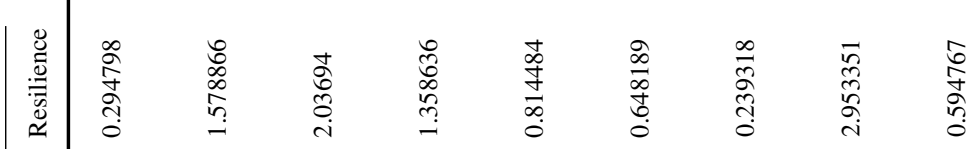

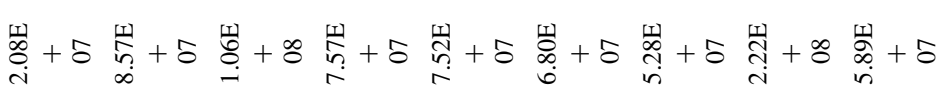

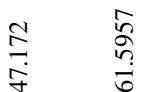

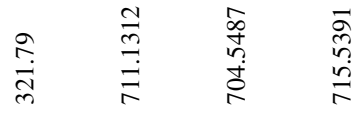

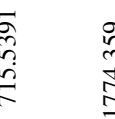

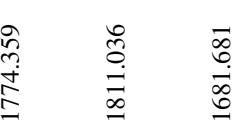

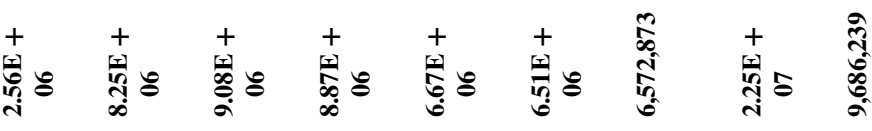

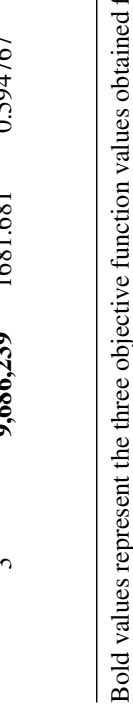




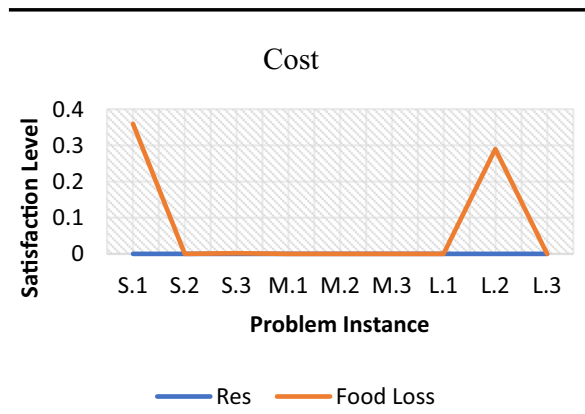

Food loss

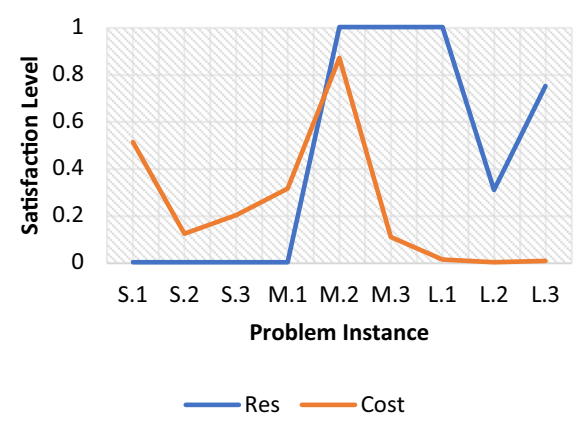

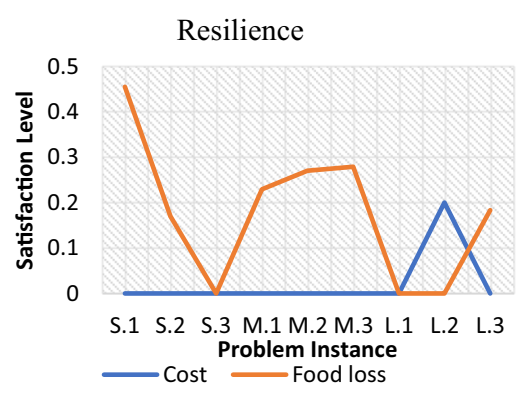

Fuzzy Multiple Objective

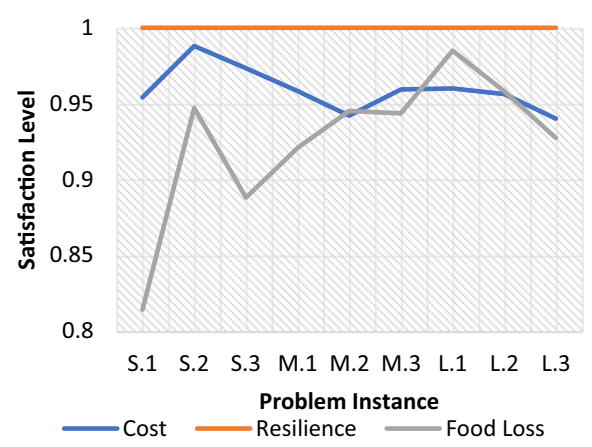

Fig. 7 Trade-off between multiple objectives

Table 9 Computational Time of the model

\begin{tabular}{lll}
\hline & Problem category & Average computing time (s) \\
\hline 1 & Small & 6.3 \\
2 & Medium & 15 \\
3 & Large & 1371 \\
\hline
\end{tabular}

the quality degradation function to account for the food loss occurring at the storage facilities at different stages of multi-echelon supply chain. The paper develops a FMOLP for integrated procurement, storage and transportation decisions in a multi-echelon agri-food supply chain considering three conflicting objectives-minimizing operational costs, minimizing quality degradation and maximizing site resilience. The paper proposes a fuzzy goal programming-based solution methodology to obtain the aggregated objective function and performs a detailed computational experimentation to study the robustness of the proposed model considering a range of problem sizes. The paper also analyses the trade-offs among three conflicting objectives of operational costs, quality degradation and resilience under single objective and multiple objectives approach. The incorporation of multiple -objective model enhances applicability of our work which considers a balanced and long-term approach towards agri-food supply chain network design. The proposed model is illustrated using a realistic case of Public Distribution System in India and long-term sustainable strategies for 
the development of resilient and well-coordinated supply network are discussed along with the operational objective of minimizing cost and food wastage.

\section{Conclusions and Future scope}

The paper models the integrated procurement, storage and transportation decisions in a multiechelon agri-food supply chain as a fuzzy multi-objective linear program (FMOLP) in order to ensure well-coordinated flow of materials across various stages. The proposed model jointly addresses the operational and strategic interests of the decision maker in the network design. It is important to establish proper infrastructure for food storage which also maintains food quality, nutrition value $\&$ prevents the food from insects, rodents or microorganisms. It is observed that the existing storage infrastructure in agri-food supply chains is inadequate in terms of capacity as well as technological infrastructure. The model evaluates the need to construct additional storage facilities at different stages of multi-echelon supply chain and proposes the framework to assess the resilience of each potential site. The resilience of potential sites is comprehensively evaluated using a set of quantitative and qualitative criteria. The strategic decision of augmenting the storage facility is integrated with the operational decision of minimizing the food loss and total operational cost across the chain. The paper also proposes the food quality degradation function with respect to storage temperature and is used to account for food loss across various stages in the supply chain. The paper provides an integrated approach of optimizing a multi-echelon agri-food supply chain configuration based three conflicting objectives of cost minimization, food loss minimization and maximizing resilience using a fuzzy goal programming-based solution methodology. The proposed model is illustrated and solved for the realistic case of Public Distribution System (PDS) in India. The government have a strategic plan to construct new silos and use them along with the existing storage facilities in order to cover the existing storage gap and minimize supply disruptions. There is also a need to improve the chain performance by minimizing the overall operational cost and reducing the food loss. Therefore, proposed FMOLP is used for this case. The detailed computational experiments are carried out in the paper to reinforce the predominance of one objective over the other two objectives when single objective focussed approach is used. It is observed that optimizing the operational cost is often the key concern for decision makers. However, our computational results reveal that it is possible to consider alternative managerial policies that can offer a different and effective compromise between the economic, resilience and food loss objectives in pursuit of a more sustainable and resilient supply chain.

This work can be extended by studying the multi-product supply chain having different harvest and procurement seasons. Future research could also focus on contrasting and connecting solutions with different strategies. In this paper, the problems of varying sizes are solved within reasonable time limit, however, for the problems of higher size computational time may significantly increase. Therefore, certain meta-heuristics can be developed to further improve the efficiency of the approach in terms of computational time.

\section{Appendix A1: Steps of TOPSIS for evaluation of sites in producing states}




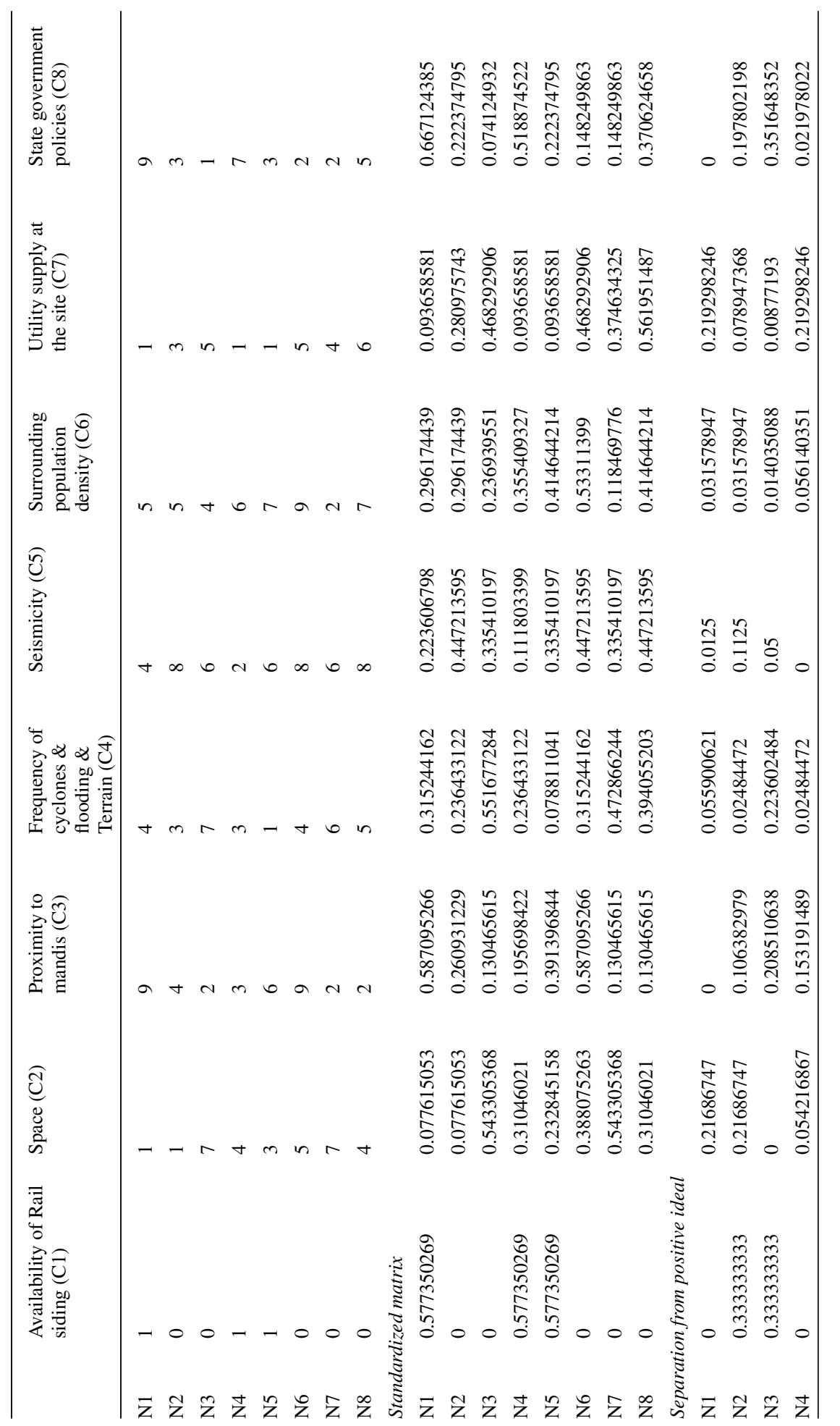




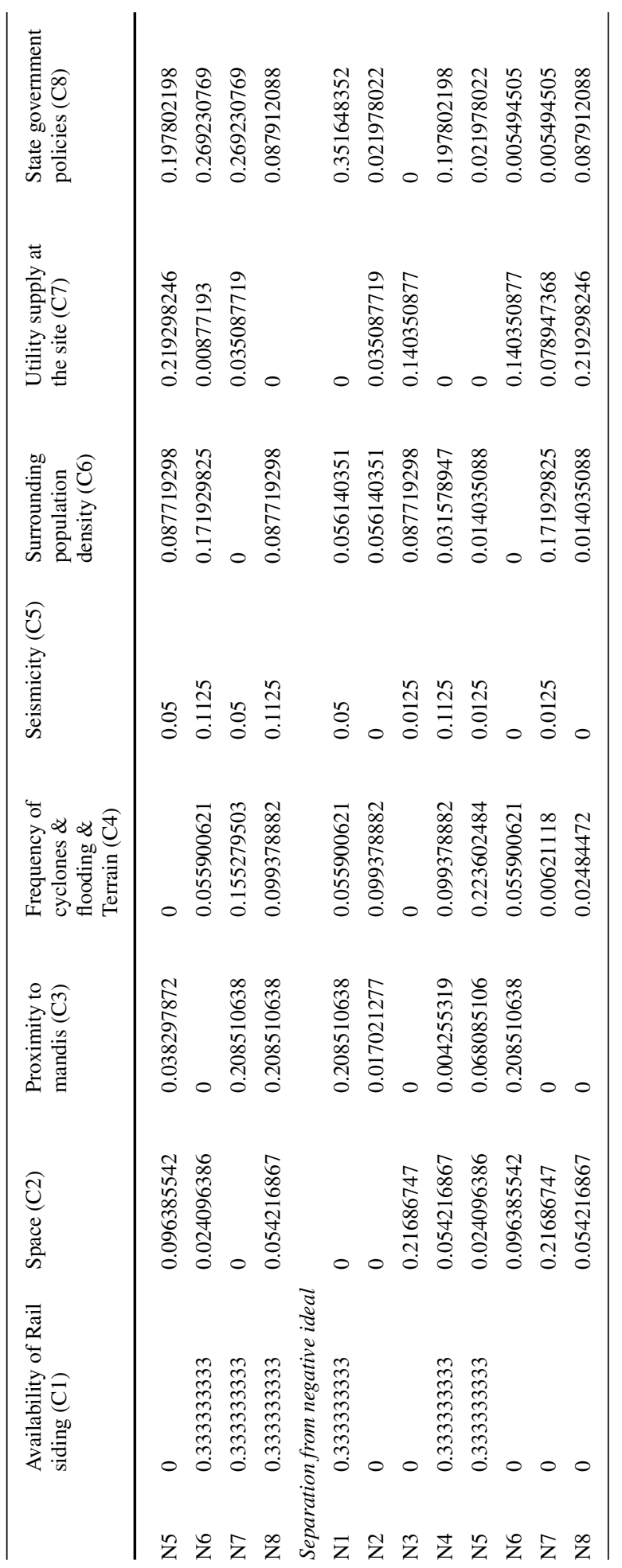




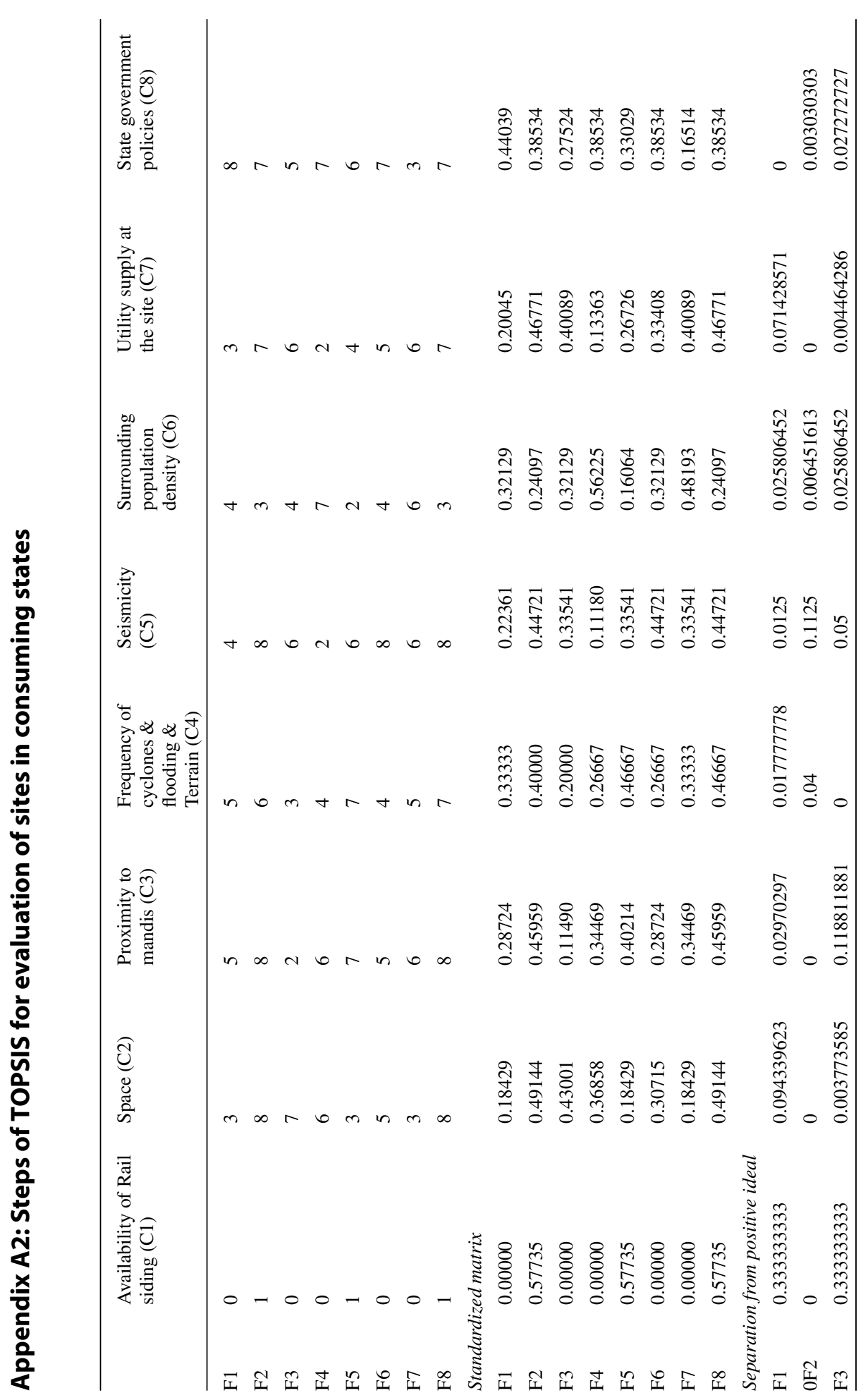




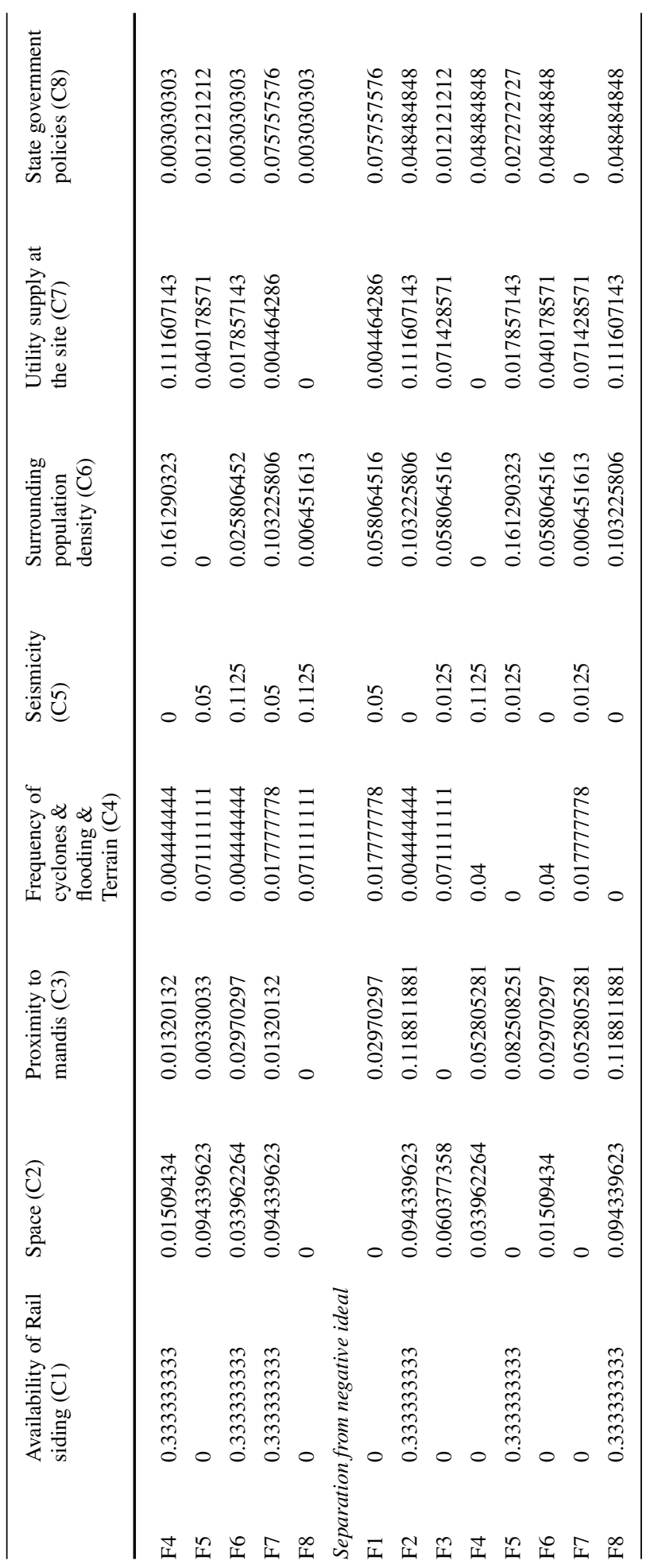




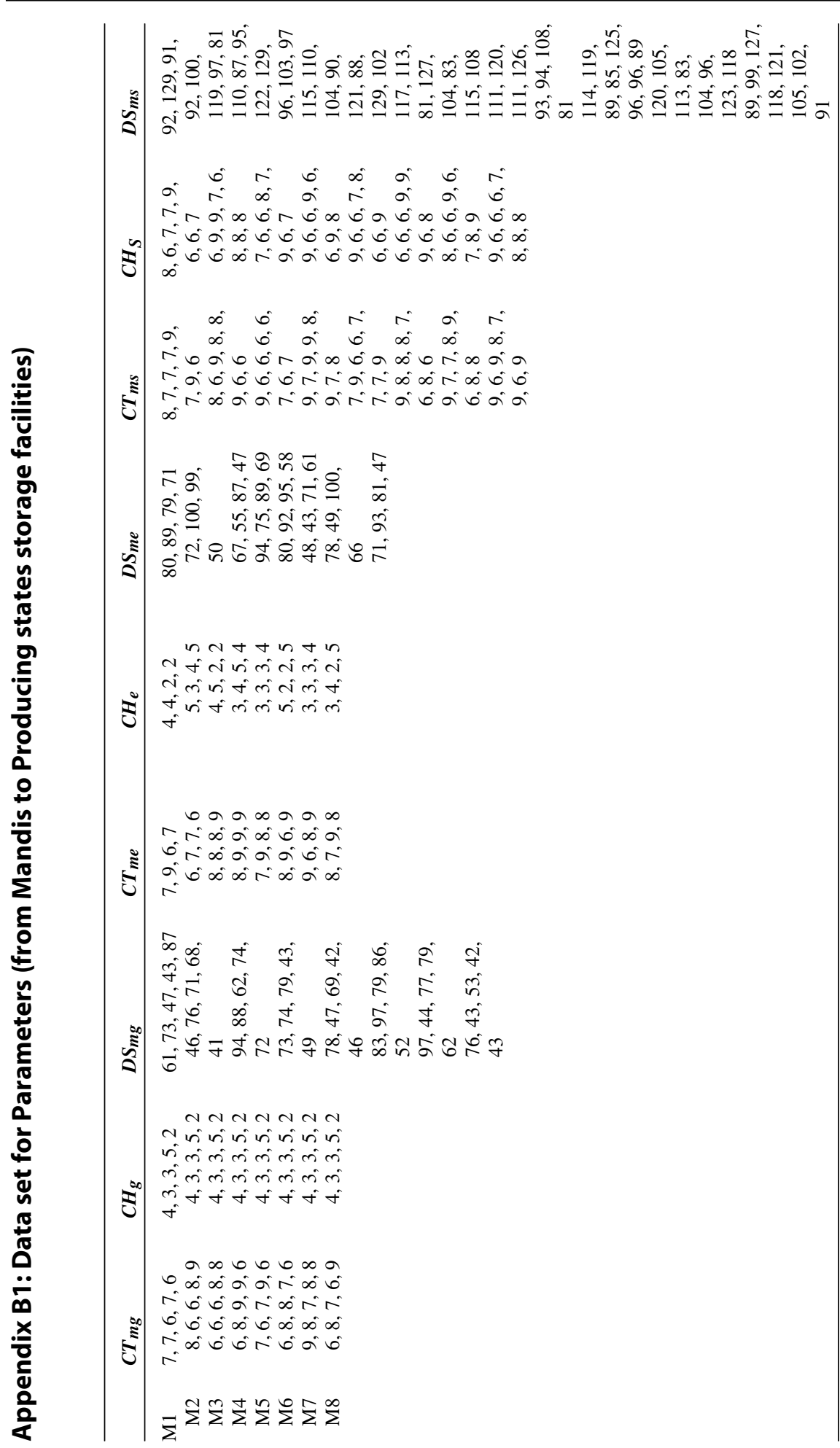




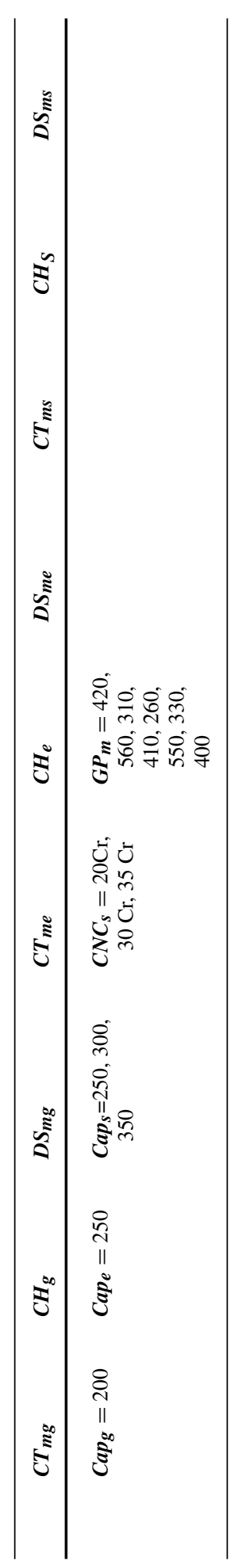

包 Springer 


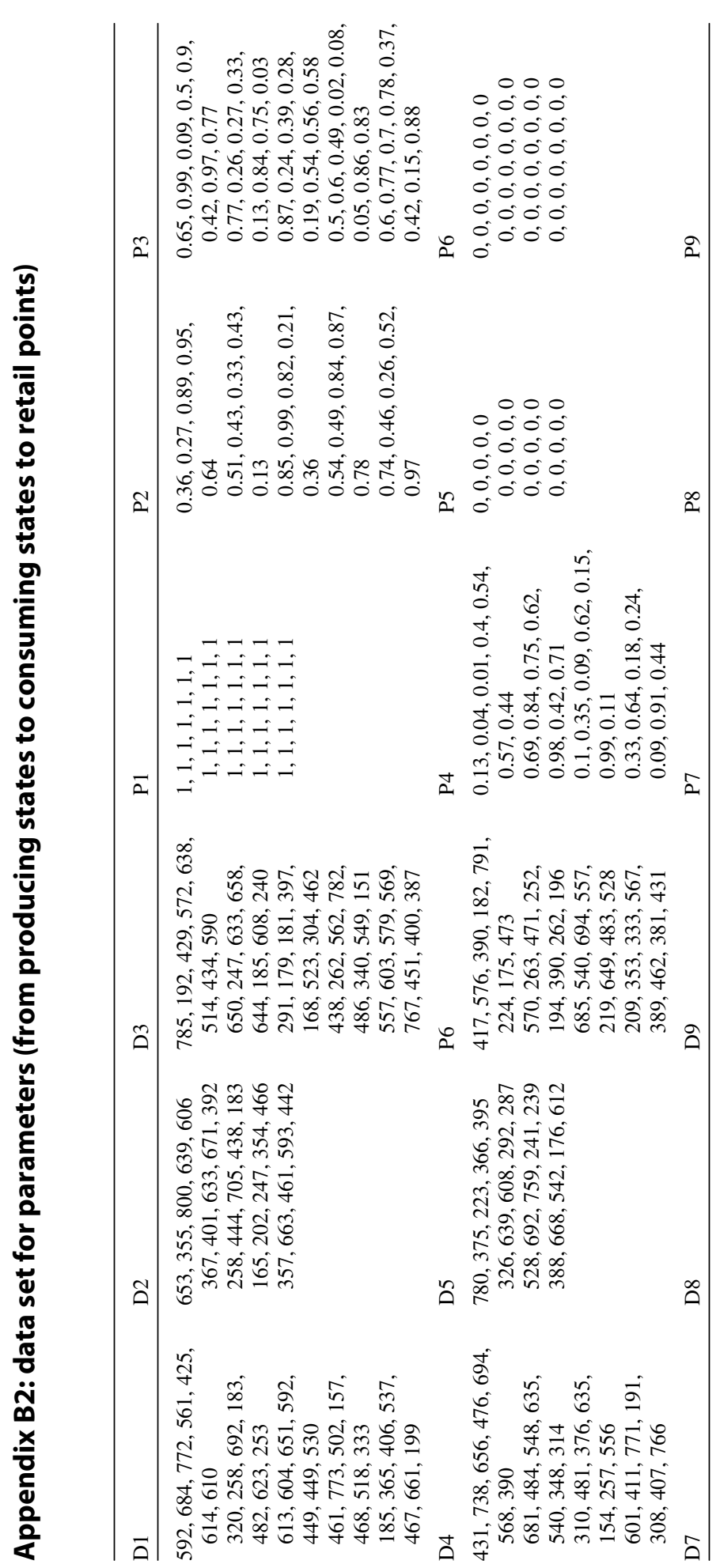


0000000

0.0000000

00000000

00000000

00000000

000000000

00000000

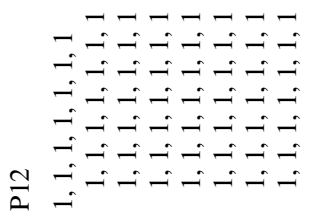

0000000

0.000000

00000000

$\begin{array}{llll} & \\ 0 & \end{array}$

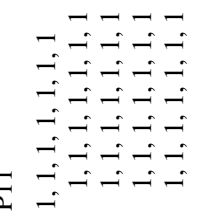

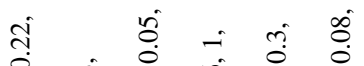

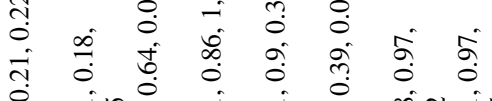

क तथ

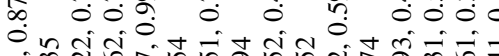

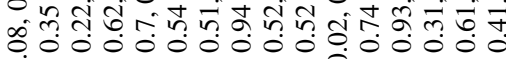

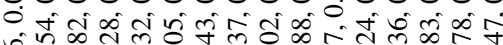

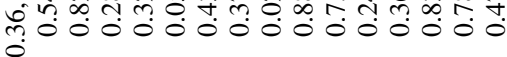

के

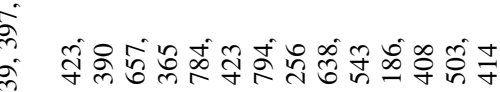

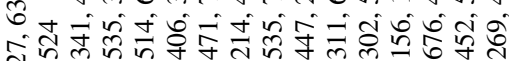

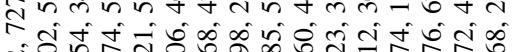

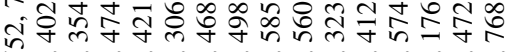

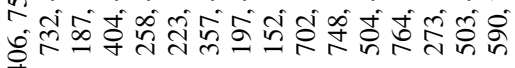

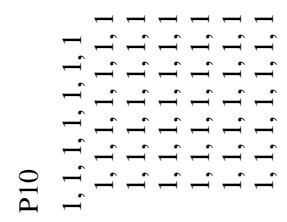

लें की में के के के तु

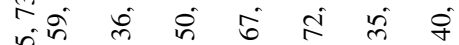

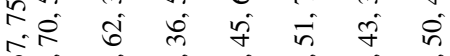
กิंกี

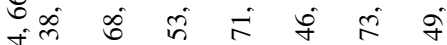

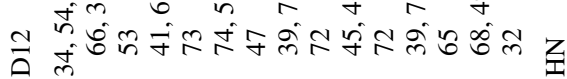

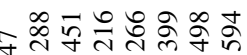

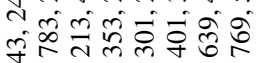

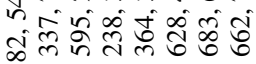

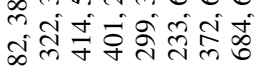

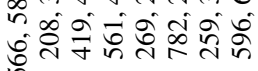

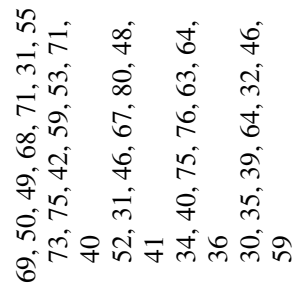

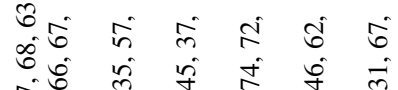

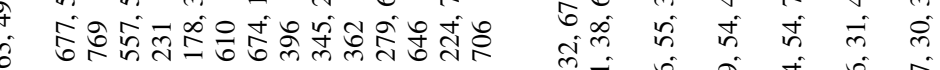

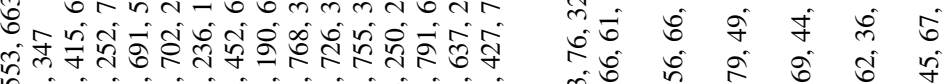




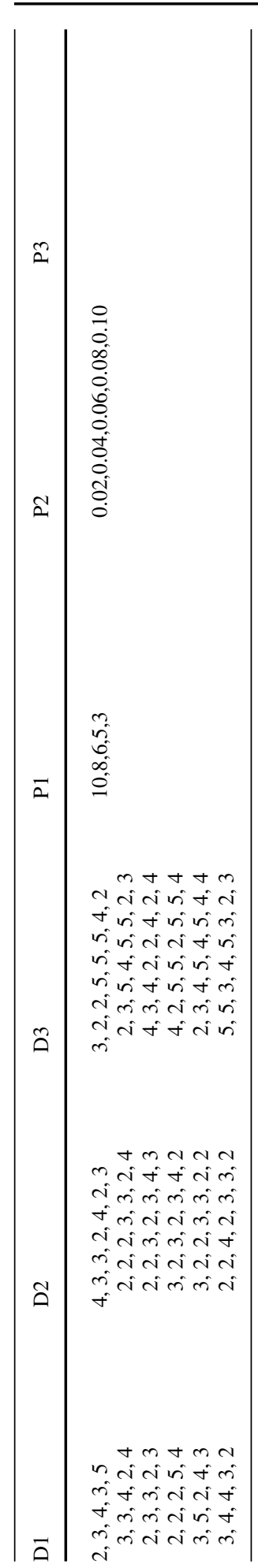




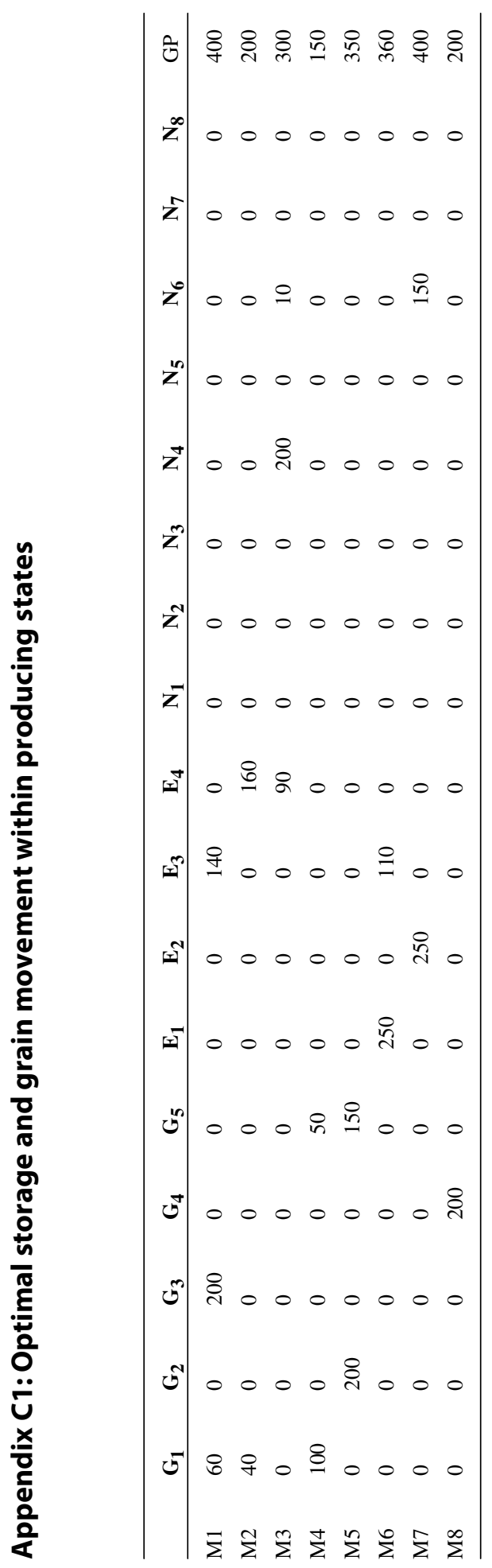




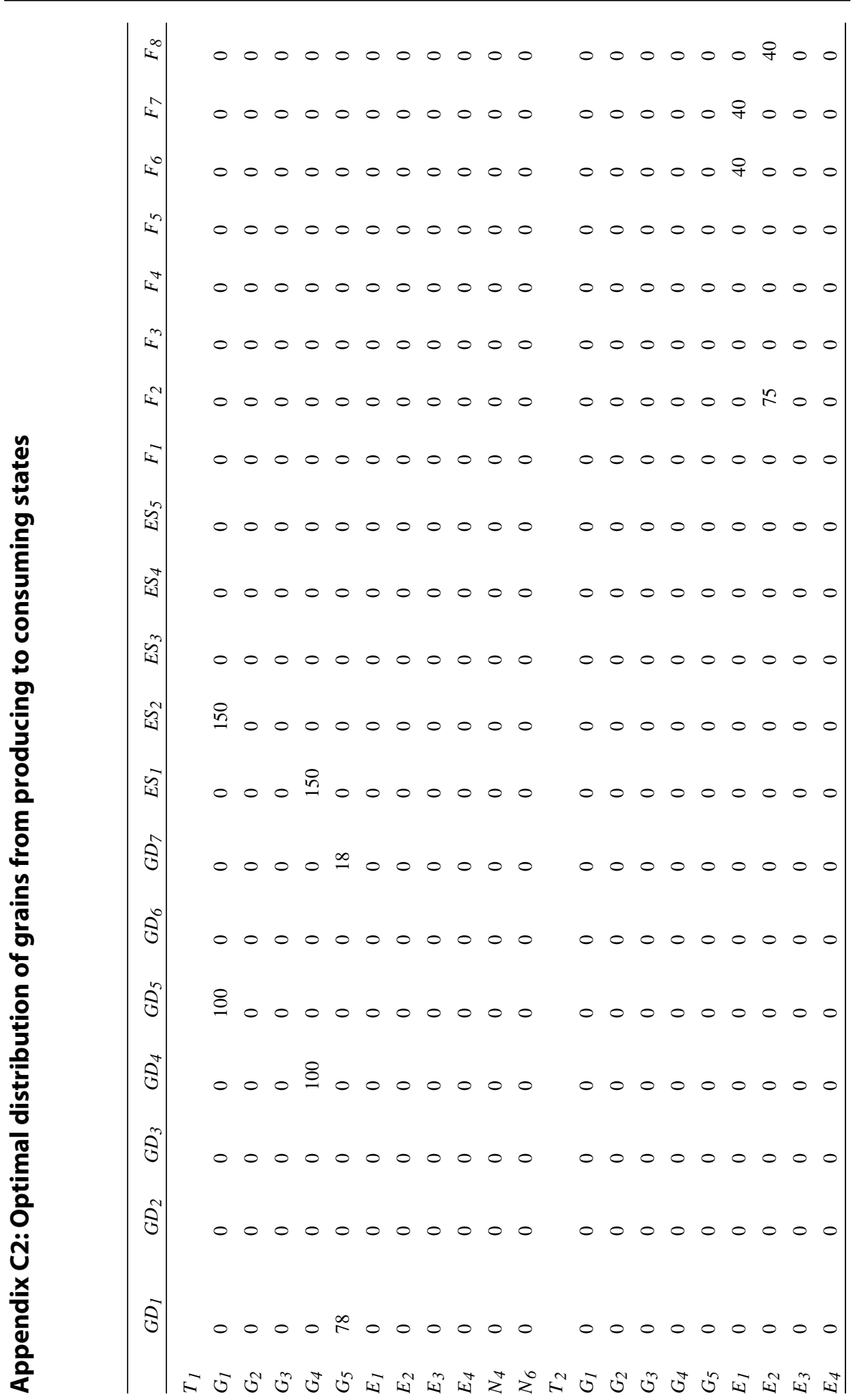




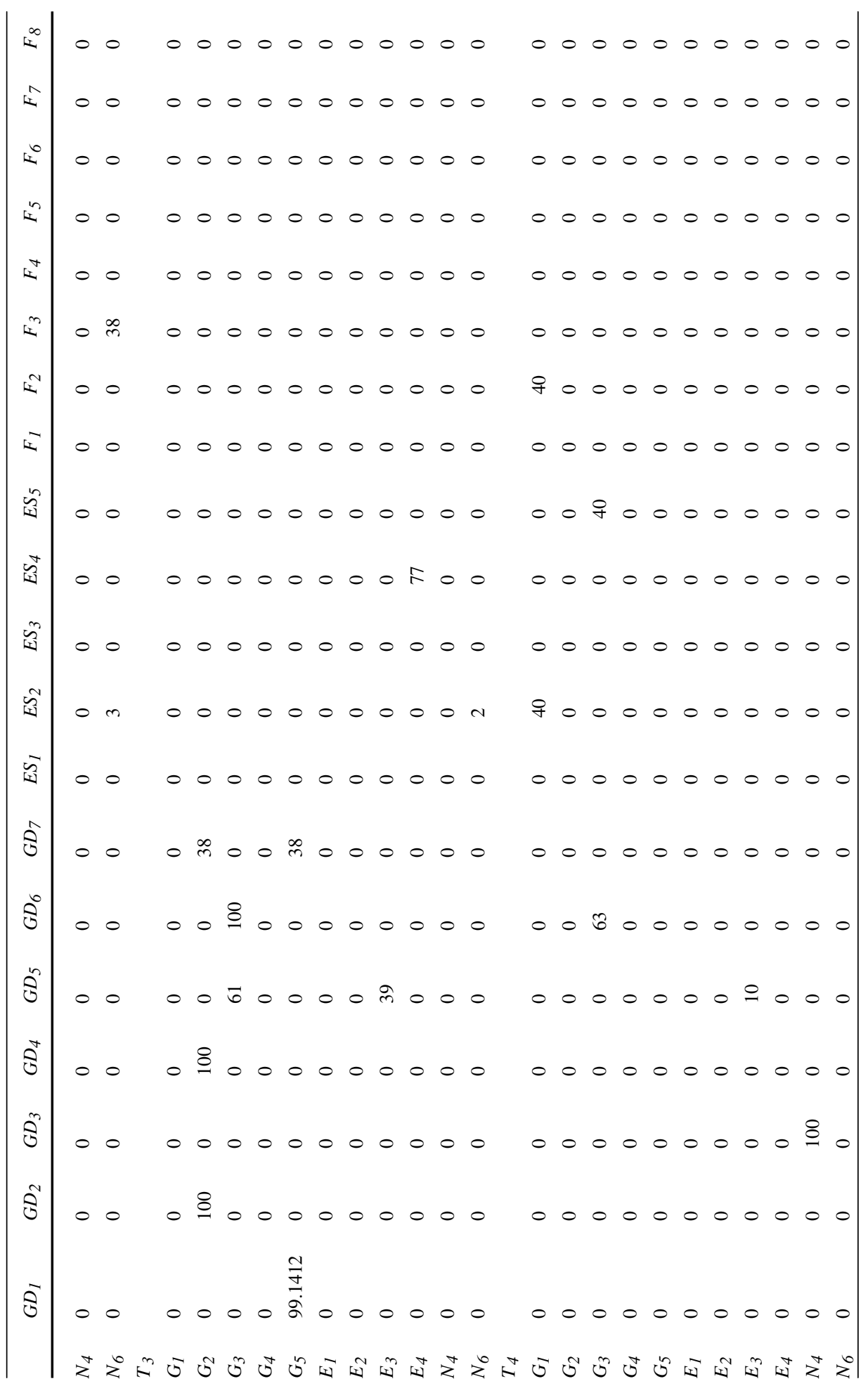




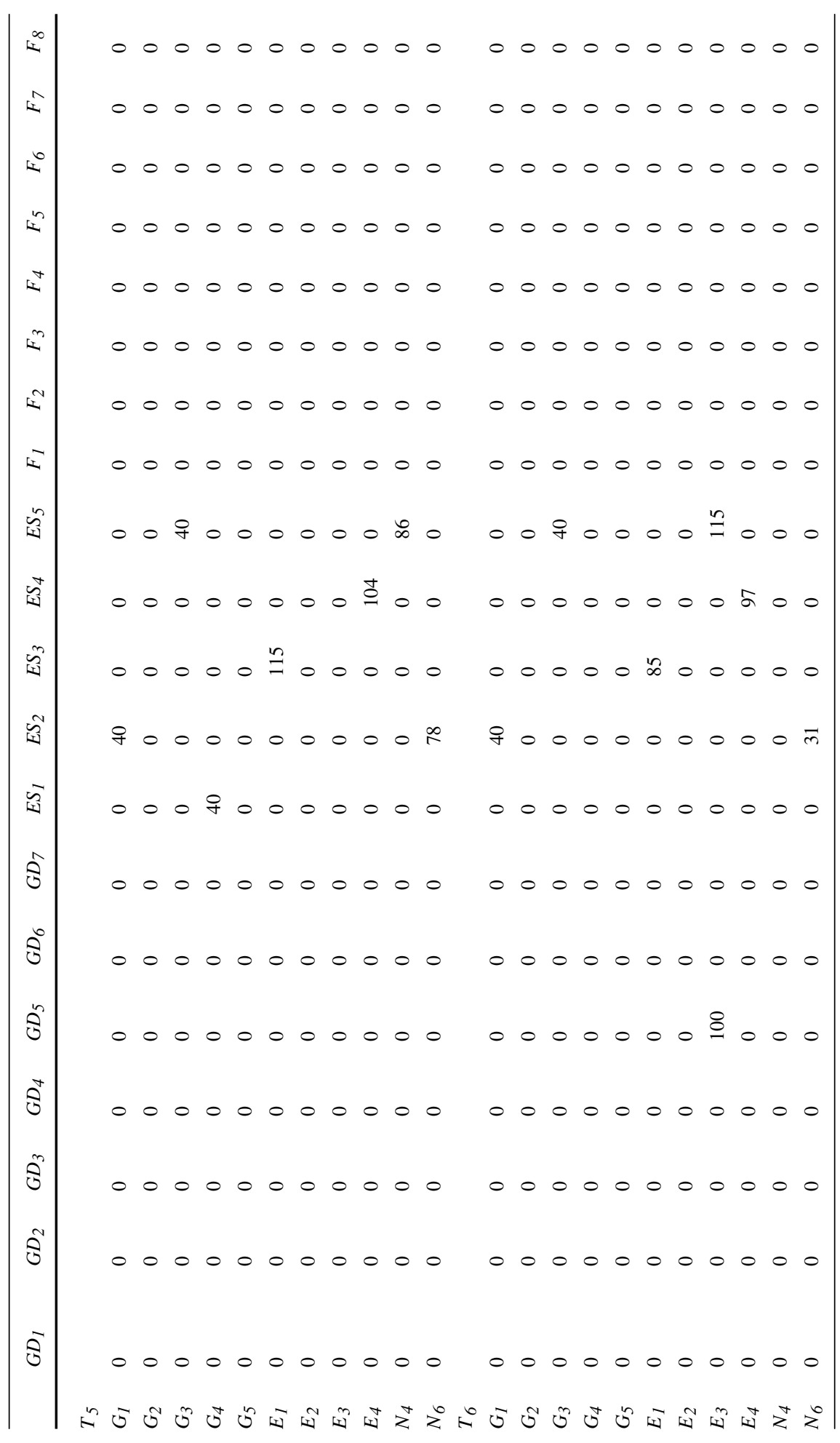


Appendix C3: Optimal quantity transported from storage facilities in consuming states to demand centres

\begin{tabular}{llllllll}
\hline & $D 1$ & $D 2$ & $D 3$ & $D 4$ & $D 5$ & $D 6$ & $D 7$ \\
\hline$T 1$ & & & & & & & \\
$G D_{1}$ & 0 & 22 & 0 & 56 & 0 & 0 & 0 \\
$G D_{2}$ & 0 & 0 & 0 & 0 & 0 & 0 & 0 \\
$G D_{3}$ & 0 & 0 & 0 & 0 & 0 & 0 & 0 \\
$G D_{4}$ & 42 & 0 & 0 & 0 & 58 & 0 & 0 \\
$G D_{5}$ & 21 & 0 & 79 & 0 & 0 & 0 & 0 \\
$G D_{6}$ & 0 & 0 & 0 & 0 & 0 & 0 & 0 \\
$G D_{7}$ & 0 & 0 & 0 & 0 & 18 & 0 & 0 \\
$E S_{1}$ & 0 & 34 & 0 & 0 & 0 & 74 & 42 \\
$E S_{2}$ & 0 & 0 & 0 & 0 & 0 & 0 & 0 \\
$E S_{3}$ & 0 & 0 & 0 & 0 & 0 & 0 & 0 \\
$E S_{4}$ & 0 & 0 & 0 & 0 & 0 & 0 & 0 \\
$E S_{5}$ & 0 & 0 & 0 & 0 & 0 & 0 & 0 \\
$F_{2}$ & 0 & 0 & 0 & 0 & 0 & 0 & 0 \\
$F_{3}$ & 0 & 0 & 0 & 0 & 0 & 0 & 0 \\
$F_{6}$ & 0 & 0 & 0 & 0 & 0 & 0 & 0 \\
$F_{7}$ & 0 & 0 & 0 & 0 & 0 & 0 & 0 \\
$F_{8}$ & 0 & 0 & 0 & 0 & 0 & 0 & 0 \\
$T 2$ & & & & & & &
\end{tabular}

$T 2$

$G D_{1} \quad 0$

$G D_{2} \quad 0 \quad 0$

$G D_{3} \quad 0 \quad 0$

$G D_{4} \quad 0 \quad 0$

$G D_{5} \quad 0 \quad 0$

$G D_{6} \quad 0 \quad 0$

$G D_{7} \quad 0 \quad 0$

$E S_{1} \quad 0 \quad 0$

$E S_{2} \quad 0 \quad 0$

$E S_{3} \quad 0 \quad 0$

$E S_{4} \quad 0 \quad 0$

$\begin{array}{lll}E S_{5} & 0 & 0\end{array}$

$F_{2} \quad 0 \quad 52$

$\begin{array}{lll}F_{3} & 38 & 0\end{array}$

$F_{6} \quad 19$

$F_{7} \quad 0 \quad 0$

$F_{8} \quad 0$

0

0

0

$0 \quad 0$

0

0

\section{0}

0

0

0

$0 \quad 0$

0

0

0

0

0

0

0

0

0

0

0

0

0

0

0

0

0

0

0

0

0

35

0

0

0

39

0

0

$\begin{array}{ll}0 & 76\end{array}$

0

0

0

0

0

0

0
0

23

23
0

0

D7

T3

\begin{tabular}{llllllll}
$G D_{1}$ & 0 & 70 & 0 & 0 & 0 & 0 & 29 \\
$G D_{2}$ & 0 & 0 & 0 & 0 & 0 & 0 & 0 \\
\hline
\end{tabular}

를 Springer 


\begin{tabular}{|c|c|c|c|c|c|c|c|}
\hline & $D 1$ & $D 2$ & D3 & $D 4$ & D5 & D6 & $D 7$ \\
\hline$G D_{3}$ & 0 & 0 & 0 & 0 & 0 & 0 & 0 \\
\hline$G D_{4}$ & 30 & 0 & 0 & 0 & 0 & 70 & 0 \\
\hline$G D_{5}$ & 0 & 0 & 0 & 0 & 0 & 0 & 0 \\
\hline$G D_{6}$ & 0 & 0 & 50 & 44 & 0 & 6 & 0 \\
\hline$G D_{7}$ & 0 & 0 & 0 & 0 & 76 & 0 & 0 \\
\hline$E S_{1}$ & 0 & 0 & 0 & 0 & 0 & 0 & 0 \\
\hline$E S_{2}$ & 0 & 0 & 0 & 0 & 0 & 0 & 0 \\
\hline$E S_{3}$ & 0 & 0 & 0 & 0 & 0 & 0 & 0 \\
\hline$E S_{4}$ & 46 & 0 & 0 & 0 & 0 & 0 & 31 \\
\hline$E S_{5}$ & 0 & 0 & 0 & 0 & 0 & 0 & 0 \\
\hline$F_{2}$ & 0 & 0 & 0 & 0 & 0 & 0 & 0 \\
\hline$F_{3}$ & 0 & 0 & 0 & 0 & 0 & 0 & 0 \\
\hline$F_{6}$ & 0 & 0 & 0 & 0 & 0 & 0 & 0 \\
\hline$F_{7}$ & 0 & 0 & 0 & 0 & 0 & 0 & 0 \\
\hline$F_{8}$ & 0 & 0 & 0 & 0 & 0 & 0 & 0 \\
\hline \multicolumn{8}{|l|}{$T 4$} \\
\hline$G D_{1}$ & 0 & 0 & 0 & 0 & 0 & 0 & 0 \\
\hline$G D_{2}$ & 0 & 9 & 0 & 0 & 0 & 33 & 53 \\
\hline$G D_{3}$ & 0 & 45 & 0 & 0 & 55 & 0 & 0 \\
\hline$G D_{4}$ & 0 & 0 & 0 & 0 & 0 & 0 & 0 \\
\hline$G D_{5}$ & 46 & 2 & 52 & 0 & 0 & 0 & 0 \\
\hline$G D_{6}$ & 0 & 0 & 0 & 50 & 0 & 13 & 0 \\
\hline$G D_{7}$ & 0 & 0 & 0 & 0 & 0 & 0 & 0 \\
\hline$E S_{1}$ & 0 & 0 & 0 & 0 & 0 & 0 & 0 \\
\hline$E S_{2}$ & 0 & 0 & 0 & 0 & 0 & 0 & 0 \\
\hline$E S_{3}$ & 0 & 0 & 0 & 0 & 0 & 0 & 0 \\
\hline$E S_{4}$ & 0 & 0 & 0 & 0 & 0 & 0 & 0 \\
\hline$E S_{5}$ & 0 & 0 & 0 & 0 & 0 & 0 & 0 \\
\hline$F_{2}$ & 0 & 0 & 0 & 0 & 0 & 0 & 0 \\
\hline$F_{3}$ & 0 & 0 & 0 & 0 & 0 & 0 & 0 \\
\hline$F_{6}$ & 0 & 0 & 0 & 0 & 0 & 0 & 0 \\
\hline$F_{7}$ & 0 & 0 & 0 & 0 & 0 & 0 & 0 \\
\hline$F_{8}$ & 0 & 0 & 0 & 0 & 0 & 0 & 0 \\
\hline \multicolumn{8}{|l|}{$T 5$} \\
\hline$G D_{l}$ & 0 & 0 & 0 & 0 & 0 & 0 & 0 \\
\hline$G D_{2}$ & 0 & 0 & 0 & 0 & 0 & 0 & 0 \\
\hline$G D_{3}$ & 0 & 0 & 0 & 0 & 0 & 0 & 0 \\
\hline$G D_{4}$ & 0 & 0 & 0 & 0 & 0 & 0 & 0 \\
\hline$G D_{5}$ & 0 & 0 & 0 & 0 & 0 & 0 & 0 \\
\hline$G D_{6}$ & 0 & 0 & 0 & 0 & 0 & 0 & 0 \\
\hline$G D_{7}$ & 0 & 0 & 0 & 0 & 0 & 0 & 0 \\
\hline$E S_{1}$ & 0 & 0 & 0 & 0 & 0 & 0 & 0 \\
\hline$E S_{2}$ & 0 & 0 & 23 & 55 & 0 & 0 & 0 \\
\hline
\end{tabular}




\begin{tabular}{|c|c|c|c|c|c|c|c|}
\hline & $D 1$ & $D 2$ & D3 & $D 4$ & D5 & D6 & D7 \\
\hline$E S_{3}$ & 0 & 62 & 0 & 0 & 0 & 53 & 0 \\
\hline$E S_{4}$ & 57 & 6.9 & 0 & 0 & 0 & 0 & 40 \\
\hline$E S_{5}$ & 0 & 0 & 33 & 0 & 53 & 0 & 0 \\
\hline$F_{2}$ & 0 & 0 & 0 & 0 & 0 & 0 & 0 \\
\hline$F_{3}$ & 0 & 0 & 0 & 0 & 0 & 0 & 0 \\
\hline$F_{6}$ & 0 & 0 & 0 & 0 & 0 & 0 & 0 \\
\hline$F_{7}$ & 0 & 0 & 0 & 0 & 0 & 0 & 0 \\
\hline$F_{8}$ & 0 & 0 & 0 & 0 & 0 & 0 & 0 \\
\hline \multicolumn{8}{|l|}{ T6 } \\
\hline$G D_{1}$ & 0 & 0 & 0 & 0 & 0 & 0 & 0 \\
\hline$G D_{2}$ & 0 & 0 & 0 & 0 & 0 & 0 & 0 \\
\hline$G D_{3}$ & 0 & 0 & 0 & 0 & 0 & 0 & 0 \\
\hline$G D_{4}$ & 0 & 0 & 0 & 0 & 0 & 0 & 0 \\
\hline$G D_{5}$ & 0 & 0 & 26 & 74 & 0 & 0 & 0 \\
\hline$G D_{6}$ & 0 & 0 & 0 & 0 & 0 & 0 & 0 \\
\hline$G D_{7}$ & 0 & 0 & 0 & 0 & 0 & 0 & 0 \\
\hline$E S_{1}$ & 0 & 0 & 0 & 0 & 0 & 0 & 0 \\
\hline$E S_{2}$ & 0 & 0 & 31 & 0 & 0 & 0 & 0 \\
\hline$E S_{3}$ & 0 & 74 & 0 & 0 & 0 & 11 & 0 \\
\hline$E S_{4}$ & 52 & 0 & 0 & 0 & 0 & 0 & 45 \\
\hline$E S_{5}$ & 0 & 0 & 13 & 0 & 48 & 53 & 0 \\
\hline$F_{2}$ & 0 & 0 & 0 & 0 & 0 & 0 & 0 \\
\hline$F_{3}$ & 0 & 0 & 0 & 0 & 0 & 0 & 0 \\
\hline$F_{6}$ & 0 & 0 & 0 & 0 & 0 & 0 & 0 \\
\hline$F_{7}$ & 0 & 0 & 0 & 0 & 0 & 0 & 0 \\
\hline$F_{8}$ & 0 & 0 & 0 & 0 & 0 & 0 & 0 \\
\hline
\end{tabular}

\section{References}

Ahumada, O., \& Villalobos, J. R. (2009). Application of planning models in the agri-food supply chain: A review. European Journal of Operational Research, 196(1), 1-20.

Allaoui, H., Guo, Y., Choudhary, A., \& Bloemhof, J. (2018). Sustainable agro-food supply chain design using two-stage hybrid multi-objective decision-making approach. Computers \& Operations Research, 89, 369-384.

Aramyan, L. H., Lansink, A. G. O., Van Der Vorst, J. G., \& Van Kooten, O. (2007). Performance measurement in agri-food supply chains: A case study. Supply Chain Management: An International Journal, 12(4), 304-315.

Asgari, N., Farahani, R. Z., Rashidi-Bajgan, H., \& Sajadieh, M. S. (2013). Developing model-based software to optimise wheat storage and transportation: A real-world application. Applied Soft Computing, 13(2), 1074-1084.

Awad, M., Ndiaye, M., \& Osman, A. (2020). Vehicle routing in cold food supply chain logistics: A literature review. The International Journal of Logistics Management, 32(2), 592-617.

Balani S (2013) Functioning of the public distribution system an analytical report. www.prsindia.org/ administrator/uploads/general/1388728622 TPDSThematicNote.pdf, Accessed 31 March 2020 
Banasik, A., Kanellopoulos, A., Claassen, G. D. H., Bloemhof-Ruwaard, J. M., \& van der Vorst, J. G. (2017). Assessing alternative production options for eco-efficient food supply chains using multi-objective optimization. Annals of Operations Research, 250(2), 341-362.

Barroso, A. P., Machado, V. H., \& Machado, V. C. (2011). Supply chain resilience using the mapping approach. In P. Li (Ed.), Supply chain management (pp. 161-184). Intech.

Bi, X., \& Zhang, D. (2016). Research of grain emergency logistics system. In 2016 4th international conference on mechanical materials and manufacturing engineering (pp. 552-554). Atlantis Press.

Bilgen, B., \& Ozkarahan, I. (2007). A mixed-integer linear programming model for bulk grain blending and shipping. International Journal of Production Economics, 107(2), 555-571.

Bottani, E., Murino, T., Schiavo, M., \& Akkerman, R. (2019). Resilient food supply chain design: Modelling framework and metaheuristic solution approach. Computers \& Industrial Engineering, 135, 177-198.

CAG (2013) Storage management and movement of food grains in Food Corporation of India, vol3.http://164.100.47.132/paperlaidfiles/CONSUMERAFFAIRS,FOODANDPUBLICDISTRIBUTION/ ReportNo7-English.pdf, Accessed 15 September 2019

Carlsson, C., \& Fullér, R. (1994). Interdependence in fuzzy multiple objective programming. Fuzzy Sets and Systems, 65(1), 19-29.

Chaboud, G. (2017). Assessing food losses and waste with a methodological framework: Insights from a case study. Resources, Conservation and Recycling, 125, 188-197.

Chiandussi, G., Codegone, M., Ferrero, S., \& Varesio, F. E. (2012). Comparison of multi-objective optimization methodologies for engineering applications. Computers \& Mathematics with Applications, 63(5), 912-942.

Chiclana, F., Herrera-Viedma, E., Herrera, F., \& Alonso, S. (2007). Some induced ordered weighted averaging operators and their use for solving group decision-making problems based on fuzzy preference relations. European Journal of Operational Research, 182(1), 383-399.

Dani, S., \& Deep, A. (2010). Fragile food supply chains: Reacting to risks. International Journal of Logistics: Research and Applications, 13(5), 395-410.

Demirel, T., Demirel, N. Ç., \& Kahraman, C. (2010). Multi-criteria warehouse location selection using Choquet integral. Expert Systems with Applications, 37(5), 3943-3952.

Diabat, A., Govindan, K., \& Panicker, V. V. (2012). Supply chain risk management and its mitigation in a food industry. International Journal of Production Research, 50(11), 3039-3050.

Esteso, A., Alemany, M. M. E., \& Ortiz, Á. (2021). Impact of product perishability on agri-food supply chains design. Applied Mathematical Modelling, 96, 20-38.

Esteso, A., Alemany, M. M., \& Ortiz, A. (2018). Conceptual framework for designing agri-food supply chains under uncertainty by mathematical programming models. International Journal of Production Research, 56(13), 4418-4446.

Fan, Y., \& Zhang, C. R. (2016, August). Robust Models for Location and Inventory Decisions in Emergencygrain Depots. In 2016 International Conference on Management Science and Management Innovation. Atlantis Press.

Galinier, P., Boujbel, Z., \& Fernandes, M. C. (2011). An efficient memetic algorithm for the graph partitioning problem. Annals of Operations Research, 191(1), 1-22.

Gholamian, M. R., \& Taghanzadeh, A. H. (2017). Integrated network design of wheat supply chain: A real case of Iran. Computers and Electronics in Agriculture, 140, 139-147.

Gokarn, S., \& Kuthambalayan, T. S. (2017). Analysis of challenges inhibiting the reduction of waste in food supply chain. Journal of Cleaner Production, 168, 595-604.

Govindan, K. (2018). Sustainable consumption and production in the food supply chain: A conceptual framework. International Journal of Production Economics, 195, 419-431.

Gupta, M., \& Mohanty, B. K. (2015). Multi-stage multi-objective production planning using linguistic and numeric data-a fuzzy integer programming model. Computers \& Industrial Engineering, 87, 454-464.

Hsiao, H. I., Van der Vorst, J. G. A. J., Kemp, R. G. M., \& Omta, S. O. (2010). Developing a decision-making framework for levels of logistics outsourcing in food supply chain networks. International Journal of Physical Distribution \& Logistics Management, 40(5), 395-414.

Hu, F. F., \& Wu, Z. H. (2010, August). Research on grain supply chain mode innovation: A case study of china non-primary grain-yielding areas. In 2010 International Conference on Management and Service Science (pp. 1-4). IEEE.

Hwang, C. L., \& Yoon, K. (1981). Methods for multiple attribute decision making. multiple attribute decision making (pp. 58-191). Berlin: Springer.

IFPRI. (2017). 2017 Global food policy report. Washington, DC: International Food Policy Research Institute. https://doi.org/10.2499/9780896292529. 
Irani, Z., Sharif, A. M., Lee, H., Aktas, E., Topaloğlu, Z., \& van't Wout, T., \& Huda, S. . (2018). Managing food security through food waste and loss: Small data to big data. Computers \& Operations Research, 98, 367-383.

Janiak, A., Kovalyov, M. Y., \& Lichtenstein, M. (2013). Strong NP-hardness of scheduling problems with learning or aging effect. Annals of Operations Research, 206(1), 577-583.

Jouzdani, J., \& Govindan, K. (2021). On the sustainable perishable food supply chain network design: A dairy products case to achieve sustainable development goals. Journal of Cleaner Production, 278, 123060.

Kaveh, M., \& Mesgari, M. S. (2019). Improved biogeography-based optimization using migration process adjustment: An approach for location-allocation of ambulances. Computers \& Industrial Engineering, $135,800-813$.

Kaveh, M., Kaveh, M., Mesgari, M. S., \& Paland, R. S. (2020). Multiple criteria decision-making for hospital location-allocation based on improved genetic algorithm. Applied Geomatics, 12(3), 291-306.

Khan, S. A. R., Razzaq, A., Yu, Z., Shah, A., Sharif, A., \& Janjua, L. (2021). Disruption in food supply chain and undernourishment challenges: An empirical study in the context of Asian countries. Socio-Economic Planning Sciences, 101033. https://doi.org/10.1016/j.seps.2021.101033.

Kusumastuti, R. D., Van Donk, D. P., \& Teunter, R. (2016). Crop-related harvesting and processing planning: A review. International Journal of Production Economics, 174, 76-92.

Leat, P., \& Revoredo-Giha, C. (2008). Building collaborative agri-food supply chains: The challenge of relationship development in the Scottish red meat chain. British Food Journal, 110(4-5), 395-411.

Maffioli, F., \& Galbiati, G. (2000). Approximability of hard combinatorial optimization problems: An introduction. Annals of Operations Research, 96(1), 221.

Maiyar, L. M., \& Thakkar \& Jitesh J. . (2017). Modelling and analysis of intermodal food grain transportation under hub disruption towards sustainability. International Journal of Production Economics, 217, 281-297.

Manders, J. H., Caniëls, M. C., \& Paul, W. T. (2016). Exploring supply chain flexibility in a FMCG food supply chain. Journal of Purchasing and Supply Management, 22(3), 181-195.

Manning, L., \& Soon, J. M. (2016). Building strategic resilience in food supply chain. British Food Journal, $118(6), 1477-1493$.

Matopoulos, A., Vlachopoulou, M., Manthou, V., \& Manos, B. (2007). A conceptual framework for supply chain collaboration: Empirical evidence from the agri-food industry. Supply Chain Management: An International Journal, 12(3), 177-186.

Matthews, N., Harrison, N., \& Steane, P. (2007). Integrating supply chain management and strategic management: the basis for analysis of the grain industry. In 9th International Decision Sciences Conference, July (pp. 11-15).

Meneghetti, A., \& Monti, L. (2015). Greening the food supply chain: An optimisation model for sustainable design of refrigerated automated warehouses. International Journal of Production Research, 53(21), 6567-6587.

Mohammed, A., \& Wang, Q. (2017). The fuzzy multi-objective distribution planner for a green meat supply chain. International Journal of Production Economics, 184, 47-58.

Mohammed, A., Harris, I., Soroka, A., \& Nujoom, R. (2019). A hybrid MCDM-fuzzy multi-objective programming approach for a G-resilient supply chain network design. Computers \& Industrial Engineering, 127, 297-312.

Mohammed, A., Harris, I., Soroka, A., Naim, M., Ramjaun, T., \& Yazdani, M. (2021). Gresilient supplier assessment and order allocation planning. Annals of Operations Research, 296(1), 335-362.

Mohebalizadehgashti, F., Zolfagharinia, H., \& Amin, S. H. (2020). Designing a green meat supply chain network: A multi-objective approach. International Journal of Production Economics, 219, 312-327.

Musavi, M., \& Bozorgi-Amiri, A. (2017). A multi-objective sustainable hub location-scheduling problem for perishable food supply chain. Computers \& Industrial Engineering, 113, 766-778.

Nardi, M. G., Sperry, S. E., \& Davis, T. D. (2007). Grain supply chain management optimization using ARCGIS in Argentina. In 2007 ESRI User Conference Proceedings (pp. 1-23). Redlands, CA: ESRI.

Özcan, T., Çelebi, N., \& Esnaf, Ş. (2011). Comparative analysis of multi-criteria decision making methodologies and implementation of a warehouse location selection problem. Expert Systems with Applications, 38(8), 9773-9779.

Paksoy, T., Pehlivan, N. Y., \& Özceylan, E. (2012). Application of fuzzy optimization to a supply chain network design: A case study of an edible vegetable oils manufacturer. Applied Mathematical Modelling, 36(6), 2762-2776.

Parfitt, J., Barthel, M., \& Macnaughton, S. (2010). Food waste within food supply chains: Quantification and potential for change to 2050. Philosophical Transactions of the Royal Society B: Biological Sciences, 365(1554), 3065-3081. 
Rajendran, S. (2003). Grain storage: Perspectives and problems. Handbook of postharvest technology: Cereals, fruits, vegetables, tea and spices (pp. 183-192). USA: Marcel Dekker.

Raut, R. D., Narkhede, B. E., Gardas, B. B., \& Raut, V. (2017). Multi-criteria decision making approach: A sustainable warehouse location selection problem. International Journal of Management Concepts and Philosophy, 10(3), 260-281.

Roh, S. Y., Jang, H. M., \& Han, C. H. (2013). Warehouse location decision factors in humanitarian relief logistics. The Asian Journal of Shipping and Logistics, 29(1), 103-120.

Rong, A., Akkerman, R., \& Grunow, M. (2011). An optimization approach for managing fresh food quality throughout the supply chain. International Journal of Production Economics, 131(1), 421-429.

Rossi, T., Pozzi, R., Pirovano, G., Cigolini, R., \& Pero, M. (2021). A new logistics model for increasing economic sustainability of perishable food supply chains through intermodal transportation. International Journal of Logistics Research and Applications, 24(4), 346-363.

Sgarbossa, F., \& Russo, I. (2017). A proactive model in sustainable food supply chain: Insight from a case study. International Journal of Production Economics, 183, 596-606.

Shareef, M. A., Dwivedi, Y. K., Kumar, V., Hughes, D. L., \& Raman, R. (2020). Sustainable supply chain for disaster management: Structural dynamics and disruptive risks. Annals of Operations Research, 1-25. https://doi.org/10.1007/s10479-020-03708-3.

Sharon, M., Abirami, C. V., \& Alagusundaram, K. (2014). Grain storage management in India. Journal of Postharvest Technology, 2(1), 12-24.

Sheffi, Y., Jr, R., \& James, B. (2015). Supply Chain View of the Resilient Enterprise, MIT Sloan Management Review. Cambridge, 47(1), 41-48.

Singh, S., Kumar, R., Panchal, R., \& Tiwari, M. K. (2021). Impact of COVID-19 on logistics systems and disruptions in food supply chain. International Journal of Production Research, 59(7), 1993-2008.

Smil, V. (2001). Feeding the world: A challenge for the twenty-first century. MIT press.

Song, C., \& Zhuang, J. (2017). Modeling a Government-Manufacturer-Farmer game for food supply chain risk management. Food Control, 78, 443-455.

Soto-Silva, W. E., Nadal-Roig, E., González-Araya, M. C., \& Pla-Aragones, L. M. (2016). Operational research models applied to the fresh fruit supply chain. European Journal of Operational Research, 251(2), 345-355.

Soysal, M., Bloemhof-Ruwaard, J. M., \& Van Der Vorst, J. G. (2014). Modelling food logistics networks with emission considerations: The case of an international beef supply chain. International Journal of Production Economics, 152, 57-70.

Soysal, M., Bloemhof-Ruwaard, J. M., Haijema, R., \& van der Vorst, J. G. (2018). Modeling a green inventory routing problem for perishable products with horizontal collaboration. Computers \& Operations Research, 89, 168-182.

Stellingwerf, H. M., Laporte, G., Cruijssen, F. C., Kanellopoulos, A., \& Bloemhof, J. M. (2018). Quantifying the environmental and economic benefits of cooperation: A case study in temperature-controlled food logistics. Transportation Research Part D: Transport and Environment, 65, 178-193.

Stone, J., \& Rahimifard, S. (2018). Resilience in agri-food supply chains: A critical analysis of the literature and synthesis of a novel framework. Supply Chain Management: An International Journal, 23(3), 207-238.

Tanksale, A., \& Jha, J. K. (2015). Implementing national food security act in India: Issues and challenges. British Food Journal, 117(4), 1315-1335.

Tanksale, A., \& Jha, J. K. (2016). An effective heuristic for multi-period multi-foodgrain inventory transportation problem in India. INFOR: Information Systems and Operational Research, 54(4), 355-379.

Taylor, D. H. (2006). Strategic considerations in the development of lean agri-food supply chains: A case study of the UK pork sector. Supply Chain Management: An International Journal, 11(3), 271-280.

Umar, M., Wilson, M., \& Heyl, J. (2017). Food network resilience against natural disasters: A conceptual framework. SAGE Open, 7(3), 2158244017717570.

Validi, S., Bhattacharya, A., \& Byrne, P. J. (2020). Sustainable distribution system design: A two-phase DoEguided meta-heuristic solution approach for a three-echelon bi-objective AHP-integrated location-routing model. Annals of Operations Research, 290(1), 191-222.

Validi, S., Bhattacharya, A., \& Byrne, P. J. (2021). An evaluation of three DoE-guided meta-heuristic-based solution methods for a three-echelon sustainable distribution network. Annals of Operations Research, 296(1), 421-469.

Van Der Vorst, J. G., Tromp, S. O., \& Zee, D. J. V. D. (2009). Simulation modelling for food supply chain redesign; integrated decision making on product quality, sustainability and logistics. International Journal of Production Research, 47(23), 6611-6631.

Yager, R. R. (1993). Families of OWA operators. Fuzzy Sets and Systems, 59(2), 125-148.

Yager, R. R. (2003). Induced aggregation operators. Fuzzy Sets and Systems, 137(1), 59-69. 
Yakavenka, V., Mallidis, I., Vlachos, D., Iakovou, E., \& Eleni, Z. (2020). Development of a multi-objective model for the design of sustainable supply chains: The case of perishable food products. Annals of Operations Research, 294(1), 593-621.

Yakovleva, N., Sarkis, J., \& Sloan, T. (2012). Sustainable benchmarking of supply chains: The case of the food industry. International Journal of Production Research, 50(5), 1297-1317.

Zhang, Y. L., \& Chen, L. (2016). Emergency materials reserve of government for natural disasters. Natural Hazards, 81(1), 41-54.

Zhu, Z., Chu, F., Dolgui, A., Chu, C., Zhou, W., \& Piramuthu, S. (2018). Recent advances and opportunities in sustainable food supply chain: A model-oriented review. International Journal of Production Research, 56(17), 5700-5722.

Zimmermann, H. J. (1978). Fuzzy programming and linear programming with several objective functions. Fuzzy Sets and Systems, 1(1), 45-55.

Publisher's Note Springer Nature remains neutral with regard to jurisdictional claims in published maps and institutional affiliations. 